Pacific Journal of Mathematics

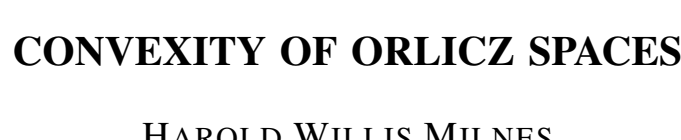




\title{
CONVEXITY OF ORLICZ SPACES
}

\author{
HAROLd Willis MiLneS
}

In a paper [1] which appeared in 1936, J. A. Clarkson defined a property of Banach spaces known as uniform convexity. Let $\|f\|$ denote the norm of an element $f$ of such a space and let $\left\{f_{n}^{\prime}, f_{n}^{\prime \prime}\right\}$ be any sequence of pairs of elements such that $\left\|f_{n}^{\prime}\right\|=\left\|f_{n}^{\prime \prime}\right\|=1$ and $\lim _{n \rightarrow \infty} \frac{1}{2}\left\|f_{n}^{\prime}+f_{n}^{\prime \prime}\right\|=1$. The space is said to be uniformly convex if these conditions imply that $\lim _{n \rightarrow \infty}\left\|f_{n}^{\prime}-f_{n}^{\prime \prime}\right\|=0$. It has been shown [2] that an equivalent definition is one in which the condition $\left\|f_{n}^{\prime}\right\|=\left\|f_{n}^{\prime \prime}\right\|=1$ may be replaced with the weaker $\left\|f_{n}^{\prime}\right\| \leqq 1$ and $\left\|f_{n}^{\prime \prime}\right\| \leqq 1$. Clarkson has been successful in showing that the Lebesgue spaces $L_{p}$ are uniformly convex if $p \neq 1$ and that $L_{1}$ is not uniformly convex. The convexity properties of more general classes of Banach spaces have been investigated by M. M. Day [3], I. Halperin [4] and E. J. McShane [7].

A concept of convexity related to uniform convexity has been described and is termed strict convexity. It is defined in the following manner. it $f^{\prime}, f^{\prime \prime}$ be any pair of elements in a Banach space such that $\left\|f^{\prime}\right\|=\left\|f^{\prime \prime}\right\|=1$ and $\frac{1}{2}\left\|f^{\prime}+f_{n}^{\prime \prime}\right\|=1$. The space is said to be strictly convex if these conditions imply that $\left\|f^{\prime}-f^{\prime \prime}\right\|=0$. In a Euclidean space, strict convexity corresponds geometrically to the property that the unit sphere $\|f\|=1$ does not contain a segment. We remark that, if a space has the property of uniform convexity, then it possesses that of strict convexity as well; however, the converse implication is generally untrue.

The principal objective of this paper is to investigate the conditions which an Orlicz space [9] must satisfy to be uniformly convex. Also the related problem of determining the conditions for strict convexity is considered. A solution to both of these questions has been presented which may be regarded as complete in the sense that both the necessary and sufficient criteria are developed.

We begin by formulating the definitions of Orlicz spaces in accordance with the notations to be used subsequently. Except in minor details we shall adopt the standard conventions. Let $v=\varphi(u)$ be a monotonically nondecreasing function not identically zero, defined for all $0 \leqq u$ such that $\varphi(u)=\varphi(u-)$ and $\varphi(0)=0$; also, let $\bar{\varphi}(u)$ denote the associated function $\bar{\varphi}(u)=\varphi(u+)$. Let $u=\psi(v)$ be the function inverse to $\varphi(u)$ which is defined by the relations:

Received December 26, 1956. This paper is part of a doctoral dissertation with the same title completed under the direction of Prof. G. G. Lorentz at Wayne State University, January, 1956. The work was in part, supported by the National Science Foundation (Grant: NSF G 1014). 
(i ) $\psi(0)=0$,

(ii) $\psi(v)=u$ if $\varphi(u)=v$ and $u$ is a point of continuity for $\varphi(u)$,

(iii) $\psi(v)=\psi(v-)$,

(iv) if $\varphi(u) \neq \bar{\varphi}(u)$, then $\psi(v)=u$ for all $\varphi(u) \leqq v \leqq \bar{\varphi}(u)$,

(v) if $\lim _{u \rightarrow \infty} \varphi(u)=l<\infty$, then $\psi(v)=+\infty$ for all $l \leqq v$.

Also, let $\bar{\psi}(v)=\psi(v+)$. Since $\varphi(u)$ and $\psi(v)$ are monotonic functions they are Lebesgue measurable and their indefinite Lebesgue integrals define the functions:

$$
\Phi(u)=\int_{0}^{u} \varphi(\bar{u}) d \bar{u} \quad \text { and } \quad \Psi(v)=\int_{0}^{v} \psi(\bar{v}) d \bar{v} .
$$

Let $\Delta$ be a measure space with a $\sigma$-finite nonatomic measure $\mu$ and a $\sigma$-ring of measurable subsets. Let $f(x)$ be a $\mu$-measurable function defined on $\Delta$; then, the functions $\varphi(|f(x)|), \bar{\varphi}(|f(x)|), \Psi(|f(x)|)$, etc., are also $\mu$-measurable on $\Delta$. For each function $f(x)$, we define:

$$
\|f\|_{\Phi}=\sup \int_{\Delta}|f(x)| g(x) d \mu
$$

where the supremum is taken for all $g(x) \geqq 0$ satisfying $\int_{\Delta} \Psi(g) d \mu \leqq 1$. The Orlicz space $L_{\Phi}=L_{\Phi}(\Delta, \mu)$ is defined to be the collection of all functions $f(x), \mu$-measurable on $\Delta$, for which $\|f\|_{\Phi}<\infty$. It may be shown (Zaanen, [10]) that the space $L_{\Phi}$ is a Banach space with the norm $\|f\|_{\Phi}$. If $\Phi(u)=u^{p}, 1 \leqq p<\infty$ then $L_{\Phi}$ is the classical Lebesgue space $L_{p}$.

Necessary and sufficient conditions for both types of convexity will be expressed directly in terms of the functions $\varphi, \psi$, etc. For strict convexity of $L_{\Phi}$ these conditions are simply that $\psi(v)$ and $\Psi(v)$ should be continuous in the extended sense. By this we mean that if $V_{0}$ is defined by $V_{0}=\sup _{\psi(v)<\infty} v$ then $\psi(v)$ and $\Psi(v)$ are continuous for $v<V_{0}$ and $\lim _{v \rightarrow V_{0}-} \psi(v)=\infty$ and $\lim _{v \rightarrow V_{0}-} \Psi(v)=\infty$. Of course, requirements additional to $\lim _{v \rightarrow V_{0}}$

those for strict convexity must be satisfied to imply uniform convexity. It is found that these conditions are alternative according as $\Delta$ is assumed to have finite or infinite measure. If $\Delta$ is of infinite measure it is necessary and sufficient that the space satisfy the following requirements: not only must the functions $\psi(v)$ and $\Psi(v)$ be continuous in the extended sense but the function $\varphi(u)$ may neither increase too rapidly nor too slowly. Precisely stated, there must be a constant $0<N<\infty$ such that $\Phi(2 u) / \Phi(u) \leqq N$ for all $0<u$ (or what is readily shown to be an equivalent statement, that there exist a constant $0<N<\infty$ such that $\varphi(2 u) / \varphi(u) \leqq N$ for all $0<u)$, and also that for each constant $0<\varepsilon<1 / 4$ there is a corresponding constant $1<R_{\varepsilon}<\infty$ such that if $0<u$ then $R_{\varepsilon}<\varphi(u) / \varphi((1-\varepsilon) u)$. When $\Delta$ is of finite measure, the func- 
tions $\psi(v)$ and $\Psi(v)$, as before, must be continuous in the extended sense; however, slightly less stringent conditions apply to the functions $\varphi(u)$ and $\Phi(u)$. It is required merely that the conditions stated for $\Delta$ of infinite measure apply only in the limiting sense; namely, that there exist a constant $0<N<\infty$ such that $\limsup _{u \rightarrow \infty} \Phi(2 u) / \Phi(u) \leqq N$ and that for each constant $0<\varepsilon<1 / 4$ there is a corresponding constant $1<R_{\varepsilon}<\infty$ such that $R_{\varepsilon}<\liminf _{u \rightarrow \infty} \varphi(u) / \varphi((1-\varepsilon) u)$.

We begin the demonstration by establishing first the statements relative to strict convexity.

LEMMA 1. If $f(x) \in L_{\Phi}$ is a step function, then

$$
\|f\|_{\Phi}=\sup _{g(x) \geqq 0} \int_{\Delta}|f| g d \mu
$$

where $\int_{\Delta} \Psi(g) d \mu \leqq 1$ and where $g(x)$ is also a step function with the same regions of constancy as $f(x)$ and $g(x)=0$ whenever $f(x)=0$.

Proof. Let $|f(x)|=f_{i}$ on sets $e_{i}$ of measure $\mu\left(e_{i}\right)=\lambda_{i}>0 i=1,2, \cdots$, $n$. Let $h(x) \geqq 0$ be any function such that $\int_{\Delta} \Psi(h) d \mu \leqq 1$. Define:

$$
g(x)=\lambda_{i}^{-1} \int_{e_{i}} h(x) d \mu=g_{i} \quad \text { on } \quad e_{i} .
$$

Since $\Psi(v)$ is the integral of a monotone nondecreasing function, it is a convex function so that by Jensen's inequality [10]:

$$
\lambda_{i}^{-1} \int_{e_{i}} \Psi(h) d \mu \geqq \Psi\left(\lambda_{i}^{-1} \int_{e_{i}} h(x) d \mu\right)=\Psi\left(g_{i}\right)
$$

and therefore:

$$
\begin{aligned}
\int_{\Delta} \Psi(g) d \mu=\sum_{i=1}^{n} \Psi\left(g_{i}\right) \lambda_{i} & \leqq \sum_{i=1}^{n} \int_{e_{i}} \Psi(h) d \mu \\
& =\int_{\Delta} \Psi(h) d \mu \leqq 1 .
\end{aligned}
$$

On the other hand:

$$
\begin{aligned}
\int_{\Delta}|f| g d \mu=\sum_{i=1}^{n} f_{i} g_{i} \lambda_{i} & =\sum_{i=1}^{n} f_{i}\left(\lambda_{i}^{-1} \int_{e_{i}} h d \mu\right) \lambda_{i} \\
& =\int_{\Delta}|f| h d \mu .
\end{aligned}
$$

It is clear that we may take $g(x)=0$ where $f(x)=0$ since the integral $\int_{\Delta}|f| g d \mu$ will remain unaltered in value while $\int_{\Delta} \Psi(g) d \mu$ can 
only become smaller.

THeOREM 1. If $\Psi(v)$ is discontinuous, then $L_{\Phi}$ is not strictly convex.

Proof. Since $\Psi(v)$ is defined as the integral of a positive function, the only type of discontinuity which can arise is of the form $\Psi\left(V_{0}\right)<\infty$ while $\Psi\left(V_{0}+\right)=\infty$ where $0<V_{0}<\infty$. (It is to be remarked that the definition of the space $L_{\Phi}$ excludes the case $V_{0}=0$ as trivial). Let $\lambda \leqq \min \left[\mu(\Delta) / 2,1 / 2 \Psi\left(V_{0}\right)\right]$ be a finite number, $A \leqq \Delta, B \leqq \Delta$ be two sets such that $A \cap B=0$ and $\mu(A)=\mu(B)=\lambda$. Define $f^{\prime}(x)=1 / \lambda V_{0}$ on $A$ and 0 elsewhere, $f^{\prime \prime}(x)=1 / \lambda V_{0}$ on $B$ and 0 elsewhere. By Lemma 1 , if $c^{\prime}$, $c^{\prime \prime}$ represent positive numbers:

$$
\begin{aligned}
& \left\|f^{\prime}\right\|_{\Phi}=\sup _{c^{\prime} \geqq 0} \frac{1}{\lambda V_{0}} \cdot \lambda c^{\prime} \quad \text { where } \quad \Psi\left(c^{\prime}\right) \leqq \frac{1}{\lambda}, \\
& \left\|f^{\prime \prime}\right\|_{\Phi}=\sup _{c^{\prime} \geqq 0} \frac{1}{\lambda V_{0}} \cdot \lambda c^{\prime \prime} \quad \text { where } \quad \Psi\left(c^{\prime \prime}\right) \leqq \frac{1}{\lambda} .
\end{aligned}
$$

Since $\Psi\left(V_{0}\right) \leqq 1 / 2 \lambda$ and $\Psi(v)=\infty$ for $V_{0}<v$ the largest value of $c^{\prime}$ or $c^{\prime \prime}$ that may be chosen is $c^{\prime}=c^{\prime \prime}=V_{0}$. Thus $\left\|f^{\prime}\right\|_{\Phi}=\left\|f^{\prime \prime}\right\|_{\Phi}=1$.

But $\frac{1}{2}\left|f^{\prime}(x)+f^{\prime \prime}(x)\right|=\frac{1}{2}\left|f^{\prime}(x)-f^{\prime \prime}(x)\right|=1 / 2 \lambda V_{0}$ on $A \cup B$ and 0 elsewhere, so that by Lemma 1 :

$$
\left\|\frac{f^{\prime}+f^{\prime \prime}}{2}\right\|_{\Phi}=\left\|\frac{f^{\prime}-f^{\prime \prime}}{2}\right\|_{\Phi}=\sup _{c \geq 0} \frac{1}{2 \lambda V_{0}} \cdot 2 \lambda c
$$

where $c$ represents any positive number with $\Psi(c) \leqq 1 / 2 \lambda$. As before, it follows the largest value of $c$ it is possible to choose is: $c=V_{0}$ so that $\frac{1}{2}\left\|f^{\prime}+f^{\prime \prime}\right\|_{\Phi}=\frac{1}{2}\left\|f^{\prime}-f^{\prime \prime}\right\|_{\Phi}=1$.

THeORem 2. If $\psi(v)$ is discontinuous, then $L_{\Phi}$ is not strictly convex.

Proof. Let $v_{0}=\sup _{\phi(v)=0} v, V_{0}=\sup _{\phi(v)<\infty} v . \quad$ By Theorem 1 it may be assumed that $\Psi(v)$ is continuous in the extended sense, so that $\lim _{v \rightarrow r_{0}-} \psi(v)=\infty$. Two cases are distinguished according as $\psi(v)$ is or is not continuous at $v=v_{0}$.

(A) $v_{0}$ is a point of discontinuity for $\psi(v)$. Let $v_{0}<\beta<V_{0}$ be a point of continuity for $\psi(v)$ and choose $\beta$ large enough so that the relation $\Psi(\beta)=1 / \lambda$ defines $\lambda \leqq \mu(\Delta) / 2$ and $\lambda<\infty$. It is then possible to determine sets $A \leqq \Delta, B \leqq \Delta$ such that: $\mu(A)=\mu(B)=\lambda$ and $A \cap B=0$. For each value of a parameter $0<p<1$ define $a_{p}=\left[1-p \bar{\psi}\left(v_{0}\right) v_{0}\right] / \beta$, $b_{p}=p \bar{\psi}\left(v_{0}\right)$ and 


$$
f_{p}(x)= \begin{cases}\frac{a_{p}}{\lambda} & \text { on } A, \\ \frac{b_{p}}{\lambda} & \text { on } B, \\ 0 & \text { on }(A \cup B)^{\prime} .\end{cases}
$$

By Lemma 1, $\left\|f_{p}\right\|_{D}=\sup _{\substack{\xi \geq 0 \\ \eta \geq 0}}\left(a_{p} \xi+b_{p} \eta\right)$ where $\Psi(\xi)+\Psi(\eta) \leqq 1 / \lambda$. Since $\Psi(v)$ is the integral of a positive non-decreasing function not identically zero, $\Psi(v)$ increases continuously to infinity; hence, it is possible to replace the condition $\Psi(\xi)+\Psi(\eta) \leqq 1 / \lambda$ by $\Psi(\xi)+\Psi(\eta)=1 / \lambda$ with $\xi \geqq v_{0}, \eta \geqq v_{0}$ for it $\xi_{1}, \eta_{1}$ satisfy $\Psi\left(\xi_{1}\right)+\Psi\left(\eta_{1}\right)<1 / \lambda$ it is always possible to find $\xi_{2} \geq \xi_{1}$, $\eta_{2} \geqq \eta_{1}$ so that $\Psi\left(\xi_{2}\right)+\Psi\left(\eta_{2}\right)=1 / \lambda$ and $\xi_{2} \geqq v_{0}, \quad \eta_{2} \geqq v_{0}$ while $a_{p} \xi_{2}+b_{p} \eta_{2} \geqq$ $a_{p} \xi_{1}+b_{p} \eta_{1}$. Thus $\eta=\eta(\xi)$ is determined as a single-valued function with $v_{0} \leqq \xi \leqq \beta$. If $I_{p}(\xi)=a_{p} \xi+b_{p} \eta(\xi)$ then $\left\|f_{p}\right\|_{\Phi}=\sup _{v_{0} \leqq \xi \leqq \beta} I_{p}(\xi)$. But $I_{p}(\xi)$ assumes its maximum subject to $v_{0} \leqq \xi \leqq \beta$ either for $\xi=v_{0}, \xi=\beta$ or at points for which $d^{+} I_{p}(\xi) / d \xi$ and $d^{-} I_{p}(\xi) / d \xi$ simultaneously change their signs, where $d^{+} / d \xi, d^{-} / d \xi$ denote respectively upper and lower derivatives. That is, the maximum must be assumed either at a boundary of the interval $v_{0} \leqq \xi \leqq \beta$ or at a turning value or a cusp. But

$$
\frac{d^{-} \eta}{d \xi}=\frac{-\bar{\psi}(\xi)}{\psi(\eta(\xi))}
$$

so that

$$
\frac{d^{-} I_{p}(\xi)}{d \xi}=a_{p}-b_{p} \frac{\bar{\psi}(\xi)}{\psi(\eta(\xi))}=\frac{1}{\beta}\left[1-p \bar{\psi}\left(v_{0}\right)\left(v_{0}+\frac{\bar{\psi}(\xi) \beta}{\psi(\eta(\xi))}\right)\right]
$$

If $p$ is any value $0<p<P$ where

$$
0<P \leqq \min \left[1,\left(\vec{\psi}\left(v_{0}\right) v_{0}+\psi(\beta) \beta\right)^{-1}\right]
$$

then $d^{-} I_{p}(\xi) / d \xi>0, v_{0}<\xi<\beta$; and since $I_{p}\left(v_{0}\right)<I_{p}(\beta)$ it follows : $\left\|f_{p}\right\|_{\Phi}=$ $I_{p}(\beta)=1$ for all such $p$. Choose $0<p^{\prime}<p^{\prime \prime}<P / 2$ and define

$$
f^{\prime}(x)=f_{p^{\prime}}(x), \quad f^{\prime \prime}(x)=f_{p^{\prime \prime}}(x) .
$$

Then $\frac{1}{2}\left(f^{\prime}(x)+f^{\prime \prime}(x)\right)=\frac{1}{2} f_{p^{\prime}+p^{\prime \prime}}(x)$ so that $\left\|f^{\prime}\right\|_{\Phi}=\left\|f^{\prime \prime}\right\|_{\Phi}=\frac{1}{2}\left\|f^{\prime}+f^{\prime \prime}\right\|_{\Phi}=1$. On the other hand $\left|f^{\prime}(x)-f^{\prime \prime}(x)\right|$ is different from zero on $B$ and therefore its norm is not zero. Thus $L_{\mathrm{\Phi}}$ fails to be strictly convex in this case.

(B) $v_{0}$ is a point of continuity for $\psi(v)$. Let $\alpha$ be a point of discontinuity for $\psi(v)$ so that $\psi(\alpha)<\bar{\psi}(\alpha) \neq 0$. Also, let $\alpha<\beta<V_{0}$ be a point of continuity for $\psi(v)$ and choose $\beta$ large enough so that the relation 
$\Psi(\alpha)+\Psi(\beta)=1 / \lambda$ defines $\lambda \leq \mu(\Delta) / 2$ and $0<\lambda<\infty$. It is then possible to determine sets $A \leqq \Delta, B \leqq \Delta$ such that $\mu(A)=\mu(B)=\lambda$ and $A \cap B=0$.

Consider the equations

$$
\left\{\begin{array} { l } 
{ a ^ { \prime } \alpha + b ^ { \prime } \beta = 1 } \\
{ a ^ { \prime } \psi ( \beta ) - b ^ { \prime } \overline { \psi } ( \alpha ) = 0 }
\end{array} \quad \left\{\begin{array}{l}
a^{\prime \prime} \alpha+b^{\prime \prime} \beta=1 \\
a^{\prime \prime} \psi(\beta)-b^{\prime \prime}\left(\frac{\psi(\alpha)+\bar{\psi}(\alpha)}{2}\right)=0 .
\end{array}\right.\right.
$$

Since $\psi(\beta) \geqq \psi(\alpha)>0$ it follows that the determinants of these equations do not vanish; therefore, the equations may be solved and it may be observed that the values of $a^{\prime}, b^{\prime}, a^{\prime \prime}, b^{\prime \prime}$ are all greater than zero. Define

$$
f^{\prime}(x)=\left\{\begin{array}{ccc}
a^{\prime} & \text { on } & A \\
\lambda & & \\
b^{\prime} & \text { on } & B \\
\lambda & & \\
0 & \text { on } & (A \cup B)^{\prime}
\end{array} \quad f^{\prime \prime}(x)=\left\{\begin{array}{lll}
\frac{a^{\prime \prime}}{\lambda} & \text { on } & A \\
b^{\prime \prime} & \text { on } & B \\
\lambda & & \\
0 & \text { on } & (A \cup B)^{\prime}
\end{array}\right.\right.
$$

By Lemma 1, $\left\|f^{\prime}\right\|_{\mathrm{D}}=\sup _{\substack{\xi \geq 0 \\ \eta \geq 0}}\left(a^{\prime} \xi+b^{\prime} \eta\right)$ where $\Psi(\xi)+\Psi(\eta) \leqq 1$. As in (A) above the condition $\Psi(\xi)+\Psi(\eta) \leqq 1 / \lambda$ may be replaced with $\Psi(\xi)+\Psi(\eta)=1 / \lambda$ and $\xi \geqq v_{0}, \eta \geqq v_{0}$ and these relationships determine $\xi=\xi(\eta)$ and $\eta=\gamma(\xi)$ as single-valued functions with $v_{0} \leqq \xi \leqq \delta$ and $v_{0} \leqq \eta \leqq \delta$ respectively where $\Psi(\delta)=1 / \lambda$. If $d^{+} / d \xi, d^{-} / d \xi$ denote respectively upper and lower derivatives, it may be seen:

$$
\begin{aligned}
\frac{d^{+} \eta}{d \xi} & =-\frac{\psi(\xi)}{\psi(\eta(\xi))}, & \frac{d^{-} \eta}{d \xi} & =-\frac{\bar{\psi}(\xi)}{\psi(\eta(\xi))}, \\
\frac{d^{+} \xi}{d \eta} & =-\frac{\psi(\eta)}{\overline{\psi(\xi(\eta))},} & \frac{d^{-} \xi}{d \eta} & =-\frac{\overline{\psi(\eta)}}{\psi(\xi(\eta))},
\end{aligned}
$$

where $\Psi(\xi)+\Psi(\eta)=1$.

If $I^{\prime}(\xi)=a^{\prime} \xi+b^{\prime} \eta(\xi)$ then $\left\|f^{\prime}\right\|_{D}=\sup _{v_{0} \leqq \xi \leqq \delta} I^{\prime}(\xi)$. As in (A), $I^{\prime}(\xi)$ assumes its maximum subject to $v_{0} \leqq \xi \leqq \delta$ either for $\xi=v_{0}, \xi=\delta$ or at points for which $d^{+} I(\xi) / d \xi$ and $d-I(\xi) / d \xi$ simultaneously change their signs. Now

$$
\lim _{\xi \rightarrow v_{0}^{+}}\left[\frac{d^{-} I^{\prime}(\xi)}{d \xi}\right]=a^{\prime}+b^{\prime}\left[\frac{d^{-} \eta(\xi)}{d \xi}\right]_{\xi \rightarrow v_{0}^{+}}=a^{\prime}-\frac{\psi\left(v_{0}\right)}{\psi(\delta)} b^{\prime}=a^{\prime}>0
$$

since $\eta=\delta$ when $\xi=v_{0}$ and $\psi(\delta)>0$. Thus, $I^{\prime}(\xi)$ increases in the immediate neighborhood of $\xi=v_{0}$ and $\xi=v_{0}$ cannot give a maximum. Also 


$$
\lim _{\xi \rightarrow \delta^{-}}\left[\frac{d^{+} I^{\prime}(\xi)}{d \xi}\right]=a^{\prime}+b^{\prime}\left[\frac{d^{+} \eta(\xi)}{d \xi}\right]_{\xi \rightarrow \delta^{-}}=a^{\prime}-b^{\prime} \lim _{\substack{\xi \rightarrow \delta^{-} \\ \eta \rightarrow v_{0}^{+}}} \frac{\psi(\xi)}{\bar{\psi}(\eta)}=-\infty
$$

since $b^{\prime}>0$. Thus $I^{\prime}(\xi)$ decreases in the immediate neighborhood of $\xi=\delta$ to the value $I^{\prime}(\delta)$ and $\xi=\delta$ cannot give a maximum.

Now

$$
\frac{d^{+} I^{\prime}(\xi)}{d \xi}=a^{\prime}-b^{\prime} \frac{\psi(\xi)}{\bar{\psi}(\eta(\xi))} \quad \text { and } \quad \frac{d^{-} I^{\prime}(\xi)}{d \xi}=a^{\prime}-b^{\prime} \frac{\bar{\psi}(\xi)}{\psi(\eta(\xi))} .
$$

Since $\left.a^{\prime} \psi(\beta)-b^{\prime} \overline{\psi(} \alpha\right)=0$ and the condition $\Psi(\xi)+\Psi(\eta(\xi))=1 / \lambda$ implies that as $\xi$ increases, $\eta$ cannot increase and conversely, a critical examination of the expressions above establishes the following relations:

$$
\begin{aligned}
& \text { if } \xi>\alpha \text { then } \frac{d^{+} I^{\prime}(\xi)}{d \xi} \leqq 0, \quad \frac{d^{-} I^{\prime}(\xi)}{d \xi} \leqq 0, \\
& \text { if } \xi=\alpha \text { then } \frac{d^{+} I^{\prime}(\xi)}{d \xi}>0, \quad \frac{d^{-} I^{\prime}(\xi)}{d \xi}=0 \text {, } \\
& \text { if } \xi<\alpha \text { then } \frac{d^{+} I^{\prime}(\xi)}{d \xi}>0, \quad \frac{d^{-} I^{\prime}(\xi)}{d \xi}>0 \text {. }
\end{aligned}
$$

Since that $d^{+} I^{\prime}(\xi) / d \xi, d^{-} I^{\prime}(\xi) / d \xi$ can change sign only once, it follows that the value $\xi=\alpha, \eta=\beta$ gives unique maximum to $I^{\prime}(\xi)$. Thus $\left\|f^{\prime}\right\|_{\Phi}=$ $a^{\prime} \alpha+b^{\prime} \beta=1$.

If $I^{\prime \prime}(\xi)=a^{\prime \prime} \xi+b^{\prime \prime} \eta(\xi)$ then an analogous argument leads to the relations

$$
\begin{aligned}
& \text { if } \xi>\alpha \text { then } \frac{d^{+} I^{\prime \prime}(\xi)}{d \xi}<0, \quad \frac{d^{-} I^{\prime \prime}(\xi)}{d \xi}<0 \text {, } \\
& \text { if } \xi=\alpha \text { then } \frac{d^{+} I^{\prime \prime}(\xi)}{d \xi}>0, \quad \frac{d-I^{\prime \prime}(\xi)}{d \xi}<0 \text {, } \\
& \text { if } \xi<\alpha \text { then } \frac{d^{+} I^{\prime \prime}(\xi)}{d \xi}>0, \quad \frac{d^{-} I^{\prime \prime}(\xi)}{d \xi}>0 \text {, }
\end{aligned}
$$

so that $\left\|f^{\prime \prime}\right\|_{\Phi}=a^{\prime \prime} \alpha+b^{\prime \prime} \beta=1$.

Consider

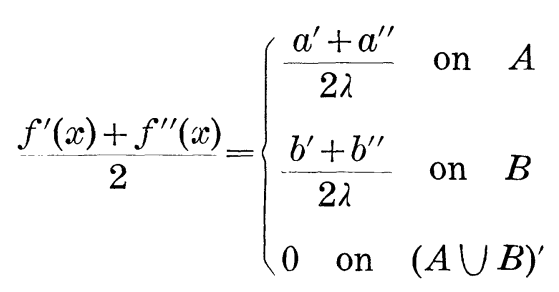


Let

$$
g(x)=\left\{\begin{array}{lll}
\alpha & \text { on } & A \\
\beta & \text { on } & B \\
0 & \text { on } & (A \cup B)^{\prime}
\end{array}\right.
$$

then

$$
\int_{\Delta} \Psi(g) d \mu=\lambda[\Psi(\alpha)+\Psi(\beta)]=1
$$

and

$$
\left\|\frac{f^{\prime}+f^{\prime \prime}}{2}\right\|_{\Phi} \geq \frac{a^{\prime}+a^{\prime \prime}}{2} \alpha+\frac{b^{\prime}+b^{\prime \prime}}{2} \beta=1
$$

Thus by the triangle inequality $\frac{1}{2}\left\|f^{\prime}+f^{\prime \prime}\right\|_{\Phi}=1$

A consideration of the defining equation shows that $b^{\prime} \neq b^{\prime \prime}$. Therefore $\left|f^{\prime}(x)-f^{\prime \prime}(x)\right|$ is not zero on $B$ and it may be concluded immediately that $\left\|f^{\prime}-f^{\prime \prime}\right\|_{\Phi} \neq 0$. Thus $L_{\Phi}$ fails to be strictly convex in this case also.

LEMma 2. If $\psi(v)$ is continuous in the extended sense and $0 \leqq v \leqq V_{0}$, $0 \leqq v^{\prime} \leqq V_{0}$ then $\Psi\left(v^{\prime}\right) \geqq \Psi(v)+\psi(v)\left(v^{\prime}-v\right)$.

Proof. If $v=v^{\prime}$ then the relation certainly holds. If $v<v^{\prime}$ then

$$
\Psi\left(v^{\prime}\right)=\int_{0}^{v^{\prime}} \psi(\bar{v}) d \bar{v}=\int_{0}^{v} \psi(\bar{v}) d \bar{v}+\int_{v}^{v^{\prime}} \psi(\bar{v}) d \bar{v} \geqq \Psi(v)+\psi(v)\left(v^{\prime}-v\right)
$$

If $v>v^{\prime}$ then

$$
\Psi\left(v^{\prime}\right)=\int_{0}^{v^{\prime}} \psi(\bar{v}) d \bar{v}=\int_{0}^{v} \psi(\bar{v}) d \bar{v}-\int_{v^{\prime}}^{v} \psi(\bar{v}) d \bar{v} \geqq \Psi(v)+\psi(v)\left(v^{\prime}-v\right) .
$$

TheOREM 3. If

(i ) $\Psi(v)$ is continuous in the extended sense,

(ii) $\psi(v)$ is continuous in the extended sense,

(iii) $f(x) \in L_{\mathrm{\phi}}$ and $|f(x)|=\mathrm{ess} \sup |f(x)|=M<\infty$ on some set of positive measure and also, when $\Delta$ is of infinite measure, $f(x)$ vanishes outside a set of finite measure; then there is a constant $0<C_{f}<\infty$ and a function $g_{f}(x) \geq 0$ such that $\|f\|_{\Phi}=\int_{\Delta} f(x) g_{f}(x) d \mu$, where $\psi\left(g_{f}(x)\right)=C_{f}|f(x)|$ and $\int_{\Delta} \Psi\left(g_{f}\right) d \mu=1$

Proof. We first establish the existence of a constant $C_{f}$ and a function $g_{f}(x)$ which satisfy the last two relations of the theorem. Let 
$E \equiv \underset{x}{E}[|f(x)|>0]$ and let $S \equiv \underset{x}{S}[|f(x)|=M]$ with $\mu(S)=\delta \neq 0$. Since $\Psi(v)$ is continuous in the extended sense and increases from zero to infinity, there is a value $v^{\prime}<V_{0}$ such that $\Psi\left(v^{\prime}\right)=1 / \delta$. With $C^{\prime}=\psi\left(v^{\prime}\right) M^{-1}$ define $g^{\prime}(x)=v^{\prime}$ for $x \in S$ and $g^{\prime}(x)=\varphi\left(C^{\prime}|f(x)|\right)$ for $x \in S^{\prime}$. Then $\psi\left(g^{\prime}(x)\right)$ $=C^{\prime}|f(x)|$ and

$$
1 \leqq \int_{\Delta} \Psi\left(g^{\prime}(x)\right) d \mu \leqq \mu(E) \cdot \delta^{-1}<\infty .
$$

Two cases will be distinguished according as

$$
\int_{\Delta} \Psi\left(\varphi\left(C^{\prime}|f|\right)\right) d \mu \leqq 1
$$

or

$$
\int_{\Delta} \Psi\left(\varphi\left(C^{\prime}|f|\right)\right) d \mu>1
$$

(A) For each value of the parameter $1 \leqq k<\infty$ define

$$
g_{k}(x)=\left\{\begin{array}{l}
\varphi\left(C^{\prime}|f(x)|\right) \text { for } x \in S^{\prime}, \\
\min \left[k \varphi\left(C^{\prime}|f(x)|\right), v^{\prime}\right] \text { for } x \in S .
\end{array}\right.
$$

The family of functions $g_{k}(x)$ is then a continuous one satisfying $\psi\left(g_{k}(x)\right)=C^{\prime}|f(x)|$ and increasing with $k$ from $g_{1}(x)=\varphi\left(C^{\prime}|f(x)|\right)$ to $g^{\prime}(x)$. The integral $I(k)=\int_{\Delta} \Psi\left(g_{k}\right) d \mu$ increases continuously from value $\leqq 1$ to values $\geq 1$. There is then a value $k_{0}$ such that $\int_{\Delta} \Psi\left(g_{k_{0}}\right) d \mu=1$. The function $g_{k_{0}}(x)=g_{f}(x)$ and the constant $C^{\prime}=C_{f}$ are those of the theorem.

(B) Let $C_{0}=\inf C$ where $\int_{\Delta} \Psi(\varphi(C|f(x)|)) d \mu \geqq 1$. Since

$$
\lim _{C \rightarrow C_{0}^{+}} \varphi(C|f(x)|)=\bar{\varphi}\left(C_{0}|f(x)|\right)
$$

it follows by Lebesgue's theorem that

$$
\int_{\Delta} \Psi\left(\bar{\varphi}\left(C_{0}|f(x)|\right) d \mu \geqq 1\right.
$$

Again, let $C^{0}=\sup C$ where

$$
\int_{\Delta} \Psi(\bar{\varphi}(C|f(x)|)) d \mu \leqq 1
$$

By the continuity of $\psi(v)$ it follows that $C^{0}=C_{0}$ and since

$$
\lim _{C \rightarrow C_{0}^{-}} \bar{\varphi}(C|f(x)|)=\varphi\left(C_{0}|f(x)|\right)
$$


then by Lebesgue's theorem $\int_{\Delta} \Psi\left(\varphi\left(C_{0}|f(x)|\right)\right) d \mu \leqq 1$. For each value of the parameter $0 \leqq k \leqq 1$ define

$$
g_{k}(x)=(1-k) \varphi\left(C_{0}|f(x)|\right)+k \bar{\varphi}\left(C_{0}|f(x)|\right)
$$

then the family of functions $g_{k}(x)$ satisfies $\psi\left(g_{k}(x)\right)=C_{0}|f(x)|$ and increases continuously with $k$ from $\varphi\left(C_{0}|f(x)|\right)$ to $\bar{\varphi}\left(C_{0}|f(x)|\right)$. The integral $I(k)=$ $\int_{\Delta} \Psi\left(g_{k}\right) d \mu$ increases continuously from values $\leqq 1$ so that there is a value $k_{0}$ such that $\int_{\Delta} \Psi\left(g_{k_{0}}\right) d \mu=1$. The constant $C_{0}=C_{f}$ and function $g_{k_{0}}(x)=g_{f}(x)$ are those of the theorem.

It is easily seen in either case (A) or (B) that $0<C_{f}$ for if $C_{f}=0$ then the corresponding function $g_{f}(x) \leqq v_{0}$ and hence $\int_{\Delta} \Psi\left(g_{f}\right) d \mu=0$ which is a contradiction of the proof already made that $\int_{\Delta} \Psi\left(g_{f}\right) d \mu=1$.

Finally, it follows from Lemma 2 that

$$
\|f\|_{\Phi}=\int_{\Delta}|f(x)| g_{f}(x) d \mu .
$$

Let $h(x) \geqq 0$ be any function such that $\int_{\Delta} \Psi(h) d \mu \leqq 1$. In Lemma 2 let $v=g_{f}(x), v^{\prime}=h(x)$; then, integrating over $\Delta$ gives

$$
\int_{\Delta} \Psi(h) d \mu \geqq \int_{\Delta} \Psi\left(g_{f}\right) d \mu+C_{f} \int_{\Delta}|f(x)|\left(h(x)-g_{f}(x)\right) d \mu
$$

or

$$
\int_{\Delta}|f(x)| g_{f}(x) d \mu \geqq \int_{\Delta}|f(x)| h(x) d \mu+\frac{1-\int_{\Delta} \Psi(h) d \mu}{C_{f}} .
$$

Since $C_{f}>0$ we obtain $\|f\|_{\Phi}=\int_{\Delta}|f(x)| g_{f}(x) d \mu$.

THEOREM 4. If

(i) the hypotheses of Theorem 3 are satisfied,

(ii) $\|f\|_{\Phi}>0$,

then

$$
\|f\|_{\Phi}=\frac{\int_{\Delta} \Phi\left(C_{f}|f|\right) d \mu+1}{C_{f}}
$$

where $C_{f}$ is the associated constant of Theorem 3. 
Proof. By Young's inequality, for arbitrary $0 \leqq u, 0 \leqq v$,

$$
u v \leqq \Phi(u)+\Psi(v)
$$

with equality if and only if at least one of the relations $v=\varphi(u)$ or $u=\psi(v)$ is satisfied. Let $u=C_{f}|f(x)|, \quad v=g_{f}(x)$ then since $\psi\left(g_{f}(x)\right)=$ $C_{f}|f(x)|$ the inequality becomes an equality and

$$
C_{f}|f(x)| g_{f}(x)=\Phi\left(C_{f}|f(x)|\right)+\Psi\left(g_{f}(x)\right) .
$$

Since $0<C_{f}<\infty$, integration over $\Delta$ gives the stated result.

THEOREM 5. If

(i) $\Psi(v)$ is continuous in the extended sense,

(ii ) $\psi(v)$ is continuous in the extended sense, then $L_{\Phi}$ is strictly convex.

Proof. Let $f^{\prime}(x), f^{\prime \prime}(x)$ be any pair of elements of $L_{\Phi}$ such that $\frac{1}{2}\left\|f^{\prime}+f^{\prime \prime}\right\|_{\Phi}=1,\left\|f^{\prime}\right\|_{\Phi}=1,\left\|f^{\prime \prime}\right\|_{\Phi}=1$. Let $f(x)=f^{\prime}(x)+f^{\prime \prime}(x)$ and

$$
S \equiv \underset{x}{S}[|f(x)|=\operatorname{ess} \sup |f(x)|]
$$

If $\mu(S)=0$ let

$$
\underset{n}{E} \equiv \underset{x}{E}\left[|f(x)| \leqq \min \left(n,\left(1-\frac{1}{n}\right) \operatorname{ess} \sup |f(x)|\right)\right] \quad(n=1,2, \cdots) ;
$$

if $\mu(S)>0$ let $E_{n}=S^{\prime}(n=1,2, \cdots)$. Let $\Delta_{n}$ be a sequence of sets snch that $\Delta_{n} \leqq \Delta_{n+1} \leqq \Delta, \mu\left(\Delta_{n}\right)<\infty, \mu\left(\Delta_{n}-E_{n}\right)>0$ and $\lim _{n} \Delta_{n}=\Delta$. If $\mu(S)=0$ define

$$
F_{n}(x)= \begin{cases}\min \left[n,\left(1-\frac{1}{n}\right) \operatorname{ess} \sup |f(x)|\right] & \text { on }\left(\Delta_{n}-E_{n}\right), \\ |f(x)| & \text { on }\left(\Delta_{n} \cap E_{n}\right), \\ 0 & \text { on } \Delta_{n}^{\prime}\end{cases}
$$

while if $\mu(S)>0$ define

$$
F_{n}(x)= \begin{cases}\operatorname{ess} \sup |f(x)| & \text { on }\left(\Delta_{n}-E_{n}\right) \\ |f(x)| & \text { on }\left(\Delta_{n} \cap E_{n}\right) \\ 0 & \text { on } \Delta_{n}^{\prime}\end{cases}
$$

observing that since $\|f\|_{\Phi}<\infty$ then ess sup $|f(x)|<\infty$ in this case. It follows easily from the definition of the norm in $L_{\Phi}$ that $\left\|F_{n}\right\|_{\Phi} \rightarrow\left\|f^{\prime}+f^{\prime \prime}\right\|_{\Phi}$. The functions $F_{n}(x)$ have been constructed in such a way that they satisfy postulate (iii) of Theorem 3 so that by this theorem and also Theorem 
4 , there are constants $\frac{1}{2} \leqq C_{n}<\infty$ and functions $g_{n}(x)$ satisfying the relations: $\psi\left(g_{n}(x)\right)=C_{n} F_{n}(x), \int_{\Delta} \Psi\left(g_{n}\right) d \mu=1$ and $\left\|F_{n}\right\|_{\Phi}=\int_{\Delta} F_{n}(x) g_{n}(x) d \mu$. Since $F_{n}(x) \leqq F_{n+1}(x)$ and $\int_{\Delta} \Psi\left(g_{n}\right) d \mu=1, \quad(n=1,2$, etc. $)$ it follows that the sequence $C_{n}$ decreases to a limit $\frac{1}{2} \leqq C<\infty$. Since $\psi\left(g_{n}(x)\right)=C_{n} F_{n}(x)$, $F_{n}(x) \leqq F_{n+1}(x)$ and $\int_{\Delta} \Psi\left(g_{n}\right) d \mu=1$ it follows by the monotone properties of $\psi(v)$ that for each arbitrarily chosen but fixed $m_{0}$ the sequence $g_{n}(x)$ ultimately decreases on $\left(\Delta_{m} \cap E_{m}\right)$. When $\mu(S)>0$ we see $\left(\Delta_{n} \cap E_{n}\right) \rightarrow$ $(\Delta-S)$ and $\left(\Delta_{n}-E_{n}\right) \rightarrow S$ so that in this event the sequence $g_{n}(x)$ decreases on $S$ also. When $\mu(S)=0$ we see as before $\left(\Delta_{n} \cap E_{n}\right) \rightarrow(\Delta-S)$ and $\left(\Delta_{n}-E_{n}\right) \rightarrow S$. Thus the sequence $g_{n}(x)$ in both cases converges in measure to its limit inferior which we denote by $g(x)$.

By Theorem 3

$$
\begin{aligned}
\left\|F_{n}\right\|_{\Phi} & =\int_{\Delta}\left|F_{n}\right| g_{n} d \mu=\int_{\Delta}\left|f^{\prime}+f^{\prime \prime}\right| g_{n} d \mu \\
& \leqq \int_{\Delta}\left|f^{\prime}\right| g_{n} d \mu+\int_{\Delta}\left|f^{\prime \prime}\right| g_{n} d \mu \leqq\left\|f^{\prime}\right\|_{\Phi}+\left\|f^{\prime \prime}\right\|_{\Phi} .
\end{aligned}
$$

Since

$$
\left\|F_{n}\right\|_{\Phi} \rightarrow\left\|f^{\prime}+f^{\prime \prime}\right\|_{\Phi}=\left\|f^{\prime}\right\|_{\Phi}+\left\|f^{\prime \prime}\right\|_{\Phi}
$$

it follows that

$$
\lim _{n} \int_{\Delta}\left|f^{\prime}\right| g_{n} d \mu=\left\|f^{\prime}\right\|_{\Phi} \quad \text { and } \quad \lim _{n} \int_{\Delta}\left|f^{\prime \prime}\right| g_{n} d \mu=\left\|f^{\prime \prime}\right\|_{\Phi} .
$$

We show that there is a constant $0<D^{\prime}<\infty$ such that $\psi(g(x))=$ $D^{\prime}\left|f^{\prime}(x)\right|$ almost everywhere. If this were not the case there is a constant $0<B<\infty$ and sets $T_{1}^{\prime}, T_{2}^{\prime}$ of finite positive measure such that

$$
\begin{gathered}
\psi(g(x))>B|f(x)| \text { on } \quad T_{1}^{\prime} \\
0<\psi(g(x))<B|f(x)| \text { on } T_{2}^{\prime} .
\end{gathered}
$$

By Egoroff's theorem we may extract subsets $T_{1}^{\prime \prime} \leqq T_{1}^{\prime}, T_{2}^{\prime \prime} \leqq T_{2}^{\prime}$ such that the sequence $g_{n}(x)$ ultimately tends uniformly to $g(x)$ on $T_{1}^{\prime \prime}$ and $T_{2}^{\prime \prime}$. From $T_{1}^{\prime \prime}, T_{2}^{\prime \prime}$ we may extract subsets $T_{1}^{\prime \prime \prime}, T_{2}^{\prime \prime \prime}$ of positive measure such that the sequence is not only bounded on $T_{1}^{\prime \prime \prime}$ and $T_{2}^{\prime \prime \prime}$ but, since $\int_{\Delta} \Psi\left(g_{n}\right) d \mu \leqq 1$ and $g(x)=\liminf g_{n}(x)$, it is also bounded away from $V_{0}$. We may again find subsets $T_{1} \leqq T_{2}^{\prime \prime \prime}$ and $T_{2} \leqq T_{2}^{\prime \prime \prime}$ such that for suitably small constants $0<t<\infty, 0<\alpha<\infty$ :

$$
\psi\left(g_{n}(x)-t^{\prime}\right)>B(|f(x)|+\alpha), \quad x \in T_{1}, 0 \leqq t^{\prime} \leqq t,
$$




$$
0<\psi\left(g_{n}(x)+t^{\prime \prime}\right)<B(|f(x)|), \quad x \in T_{2}, 0 \leqq t^{\prime \prime} \leqq t,
$$

for all $n$ sufficiently large.

Since $\int_{\Delta}\left|f^{\prime}\right| g_{n} d \mu \rightarrow\left\|f^{\prime}\right\|_{\Phi}$, for each $0<\varepsilon$ there is an $n_{\varepsilon}$ such such that if $n_{\varepsilon} \leqq n$ then: $\int_{\Delta}\left|f^{\prime}\right| h d \mu-\int_{\Delta}\left|f^{\prime}\right| g_{n} d \mu<\varepsilon$ where $h(x) \geqq 0$ is any function with $\int_{\Delta} \Psi(h) d \mu \leqq 1$. Also, since $g(x)$ is bounded away from $V_{0}$ and the sequence $g_{n}(x)$ converges uniformly on $T_{1}$ to $g(x)$, there is a constant $0<\beta<\infty$ such that for sufficiently large $n$

$$
\int_{T_{1}} \psi\left(g_{n}(x)\right) d \mu \leqq \int_{T_{1}} \psi(g(x)+\beta) d \mu<\infty
$$

Let

$$
0<\varepsilon<\alpha \mu\left(T_{1}\right) \min \left[t, \frac{t \int_{T_{2}} \psi(g(x)) d \mu}{\int_{T_{1}} \psi(g(x)+\beta) d \mu}\right]
$$

and choose $n \geqq n_{\varepsilon}$ so that (2) holds. Then, if

$$
\int_{T_{1}} \Psi\left(g_{n}\right) d \mu+\int_{T_{2}} \Psi\left(g_{n}\right) d \mu=b
$$

and if $0<t_{1}<\infty, 0<t_{2}<\infty$ also satisfy

$$
\int_{T_{1}} \Psi\left(g_{n}(x)-t_{1}\right) d \mu+\int_{T_{2}} \Psi\left(g_{n}(x)+t_{2}\right) d \mu=b
$$

we have by the mean value theorem, for some $0 \leqq \theta_{1} \leqq 1,0 \leqq \theta_{2} \leqq 1$,

$$
-t_{1} \int_{T_{1}} \psi\left(g_{n}(x)-\theta_{1} t_{1}\right) d \mu+t_{2} \int_{T_{2}} \psi\left(g_{n}(x)+\theta_{2} t_{2}\right) d \mu=0 .
$$

Thus, if

$$
t_{1}=\min \left[t, \frac{t \int_{T_{2}} \psi(g(x)) d \mu}{\int_{T_{1}} \psi(g(x)+\beta) d \mu}\right]
$$

then $t_{2} \leqq t$. Now by (1)

$$
\begin{aligned}
-t_{1} \int_{T_{1}} \psi\left(g_{n}(x)-\theta_{1} t_{1}\right) d \mu \leqq-B t_{1} \int_{T_{1}}|f| d \mu-B t_{1} \alpha \mu\left(T_{1}\right) \\
\quad t_{1} \int_{T_{2}} \psi\left(g_{n}(x)+\theta_{2} t_{2}\right) d \mu \leqq B t_{2} \int_{T_{2}}|f| d \mu,
\end{aligned}
$$


so that by (5)

$$
-t_{1} \int_{T_{1}}|f| d \mu+t_{2} \int_{T_{2}}|f| d \mu \geqq t_{1} \alpha \mu\left(T_{1}\right)>\varepsilon
$$

But if

$$
h(x)=\left\{\begin{array}{lll}
g_{n}(x)-t_{1} & \text { on } & T_{1} \\
g_{n}(x)+t_{2} & \text { on } & T_{2} \\
g_{n}(x) & \text { on } & \left(T_{1} \cup T_{2}\right)^{\prime}
\end{array}\right.
$$

then by (3) and (4) $\int_{\Delta} \Psi(h) d \mu=\int_{\Delta} \Psi\left(g_{n}\right) d \mu=1$ while

$$
\begin{aligned}
\int_{\Delta}\left|f^{\prime}\right| h d \mu & =\int_{\Delta}\left|f^{\prime}\right| g_{n} d \mu-t_{1} \int_{T_{1}}\left|f^{\prime}\right| d \mu+t_{1} \int_{T_{2}}\left|f^{\prime}\right| d \mu \\
& \geq \int_{\Delta}\left|f^{\prime}\right| g_{n} d \mu+\varepsilon,
\end{aligned}
$$

which contradicts the demonstration already made that $\int_{\Delta}\left|f^{\prime}\right| h d \mu-$ $\int_{\Delta}\left|f^{\prime}\right| g_{n} d \mu<\varepsilon$. Thus, there is a constant $0<D^{\prime}<\infty$ such that $\psi(g(x))=$ $D^{\prime}\left|f^{\prime}(x)\right|$. Similarly, there is a constant $0<D^{\prime \prime}<\infty$ such that $\psi(g(x))=$ $D^{\prime \prime}\left|f^{\prime \prime}(x)\right|$.

Since $\left|f^{\prime}(x)\right|=\psi(g(x)) / D^{\prime}$ and $\left|f^{\prime \prime}(x)\right|=\psi(g(x)) / D^{\prime \prime}$ we see $\left|f^{\prime}(x)\right|$ and $\left|f^{\prime \prime}(x)\right|$ differ at most by a constant factor. But $\left\|f^{\prime}\right\|_{\Phi}=\left\|f^{\prime \prime}\right\|_{\Phi}=1$ so that this factor is unity. Thus, $f^{\prime}(x)$ and $f^{\prime \prime}(x)$ differ at most in sign. But $\psi^{\prime}(g(x))=C\left|f^{\prime}(x)+f^{\prime \prime}(x)\right|$ so that if $f^{\prime}(x)=-f^{\prime \prime}(x)$ at any point, then $\psi(g(x))=D^{\prime}\left|f^{\prime}(x)\right|=D^{\prime \prime}\left|f^{\prime \prime}(x)\right|=0$ at this same point. Hence $f^{\prime}(x)=f^{\prime \prime}(x)$ almost everywhere and $\left\|f^{\prime}-f^{\prime \prime}\right\|_{\Phi}=0$.

Theorems 1, 2 and 5 together have established the necessary and sufficient conditions for the strict convexity of the spaces $L_{\phi}$. In order to proceed with the more difficult demonstrations for uniform convexity we shall require the following important proposition relating to the norm of an element in $L_{\Phi}$.

THEOREM 6 . If

(i) $\psi(v)$ is continuous in the extended sense,

(ii) $\Psi(v)$ is continuous in the extended sense,

(iii) (a) there is a constant $0<N<\infty$ such that $\Phi(2 u) / \Phi(u) \leqq N$, $(0<u)$, when $\Delta$ is of infinite measure,

(b) $\limsup _{u \rightarrow \infty} \Phi(2 u) / \Phi(u)<+\infty$ when $\Delta$ is of finite measure, then for each $f \in L_{\phi}$ different from zero there is a constant $C_{f}$ and a function $g_{f}(x) \geqq 0$ such that 


$$
\begin{gathered}
\|f\|_{\Phi}=\int_{\Delta}|f| d \mu, \\
\psi\left(g_{f}(x)\right)=C_{f}|f(x)| \quad \text { and } \int_{\Delta} \Psi\left(g_{f}\right) d \mu=1 .
\end{gathered}
$$

Proof. Let

$$
S=\underset{x}{S}[|f(x)|=\operatorname{ess} \sup |f(x)|]
$$

If $\mu(S)=0$, let

$$
\underset{n}{E} \equiv \underset{x}{E}\left[|f(x)| \leqq \min \left(n,\left(1-\frac{1}{n}\right) \operatorname{ess} \sup |f(x)|\right)\right], \quad(n=1,2, \cdots) ;
$$

if $\mu(S)>0$ let $E=S^{\prime},(n=1,2, \cdots)$. Let $\Delta_{n}$ be a sequence of sets such that $\Delta_{n} \leqq \Delta_{n+1} \leqq \Delta, \mu\left(\Delta_{n}\right)<\infty, \mu\left(\Delta_{n}-E_{n}\right)>0$ and $\lim \Delta_{n}=\Delta$. If $\mu(S)=0$, define

$$
F_{n}(x)=\left\{\begin{array}{l}
\min \left[n,\left(1-\frac{1}{n}\right) \operatorname{ess} \sup |f(x)|\right] \text { on }\left(\Delta_{n}-E_{n}\right), \\
|f(x)| \text { on }\left(\Delta_{n} \cap E_{n}\right) \\
0 \text { on } \Delta_{n}^{\prime}
\end{array}\right.
$$

while if $\mu(S)>0$, define

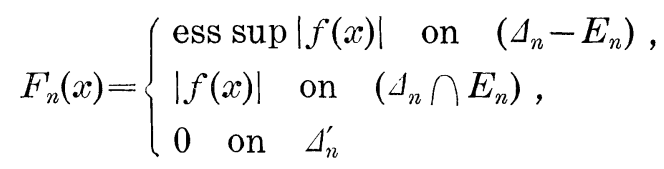

observing that in this case ess sup $|f(x)|<\infty$ since $\|f\|_{1}<\infty$. The functions $F_{n}(x)$ satisfy the postulates of Theorems 3 and 4 so that there are constants $\left\|F_{n}\right\|_{\Phi}^{-1} \leqq C_{n}<\infty$ and functions $g_{n}(x) \geqq 0$ such that $\left\|F_{n}\right\|_{\Phi}^{-1} \leqq C_{n}<\infty$ and functions $g_{n}(x) \geqq 0$ such that $\left\|F_{n}\right\|_{\Phi}=\int_{\Delta} F_{n} g_{n} d \mu$ where $\psi\left(g_{n}(x)\right)=$ $C_{n} \cdot F_{n}(x)$ and $\int_{\Delta} \Psi\left(g_{n}\right) d \mu=1$. Since $F_{n}(x) \leqq F_{n+1}(x) \leqq|f(x)|$ it follows from the condition $\int_{\Delta} \Psi\left(g_{n}\right) d \mu=1$ that the sequence $C_{n}$ cannot increase and since $\|f\|_{\Phi} \geqq\left\|F_{n}\right\|_{\Phi}$ it has a limit $\|f\|_{\Phi}^{-1} \leqq C<\infty$. Since $\psi\left(g_{n}(x)\right)=$ $C_{n} F_{n}(x), \quad F_{n}(x) \leqq F_{n+1}(x)$ and $\int_{\Delta} \Psi\left(g_{n}\right) d \mu=1$ it follows by the monotone properties of $\psi(v)$ that for each arbitrarily chosen but fixed $m$ the sequence $g_{n}(x)$ ultimately decreases on $\left(A_{m} \cap E_{m}\right)$. When $\mu(S)>0$ we see $\left(\Delta_{n} \cap E_{n}\right) \rightarrow(\Delta-S)$ and $\left(\Delta_{n}-E_{n}\right) \rightarrow S$, so that in this event the sequence $g_{n}(x)$ decreases on $S$ also. When $\mu(S)=0$ we see $\left(\Delta_{n} \cap E_{n}\right) \rightarrow(\Delta-S)$ and $\left(\Delta_{n}-E_{n}\right) \rightarrow S$. Thus, the sequence $g_{n}(x)$ in both cases converges in 
measure to its limit inferior, which we denote by $g(x)$.

(a) Assume that postulate (iii) (a) holds. In this case there is a constant $0<M<\infty$ such that $\bar{\varphi}(2 u) \leqq M \varphi(u)$ for $0<u$. Thus, if $\Phi(2 u) \leqq N \Phi(u)$ for $0<u$ then $\Phi(4 u) \leqq N^{2} \Phi(u)$. Suppose there were a sequence $0<u_{n}$ such that for each natural number $\bar{\varphi}\left(2 u_{n}\right)>n \varphi\left(u_{n}\right)$, then

$$
\Phi\left(4 u_{n}\right) \geqq \int_{: u_{n}}^{1 u_{n}} \varphi(\bar{u}) d \bar{u} \geqq 2 u_{n} \bar{\varphi}\left(2 u_{n}\right) \geqq 2 n u_{n} \varphi\left(u_{n}\right) \geqq 2 n \Phi\left(u_{n}\right)
$$

since $u_{n} \varphi\left(u_{n}\right) \geqq \phi\left(u_{n}\right)$. Now

$$
\int_{\Delta}|f| \bar{\varphi}(2 C|f|) d \mu \leqq M \int_{\Delta}|f| \varphi(C|f|) d \mu \leqq M\|f\|_{\Phi}
$$

since

$$
\int_{\Delta} \Psi(\varphi(C|f|)) d \mu \leqq \int_{\Delta} \lim \inf \Psi\left(g_{n}\right) d \mu \leqq \liminf \int_{\Delta} \Psi\left(g_{n}\right) d \mu=1
$$

by Fatou's lemma. By Young's inequality

$$
\begin{aligned}
\int_{\Delta} \Psi(\bar{\varphi}(2 C|f|) d \mu & =2 C \int_{\Delta}|f| \bar{\varphi}(2 C|f|) d \mu-\int_{\Delta} \Phi(2 C|f|) d \mu \\
& \leqq 2 C M\|f\|_{\Phi}<\infty .
\end{aligned}
$$

But for all $n$ sufficiently large $\bar{\varphi}(2 C|f(x)|) \geqq g_{n}(x) \geqq g(x)$ therefore by the monotone property of $\Psi(v)$ and Lebesgue's theorem

$$
1=\liminf \int_{\Delta} \Psi\left(g_{n}\right) d \mu=\int_{\Delta} \liminf \Psi\left(g_{n}\right) d \mu=\int_{\Delta} \Psi(g) d \mu
$$

Let $h(x) \geqq 0$ be any function such that $\int_{\Delta} \Psi(h) d \mu \leqq 1$. In Lemma 2 let $v=g(x), v^{\prime}=h(x)$; then integrating over $\Delta$ gives

$$
\int_{\Delta} \Psi(h) d \mu \geqq \int_{\Delta} \Psi(g) d \mu+C \int_{\Delta}|f|(h-g) d \mu
$$

or

$$
\int_{\Delta}|f| g d \mu \geqq \int_{\Delta}|f| h d \mu+\frac{1-\int_{\Delta} \Psi(h) d \mu}{C} .
$$

Since $C>0$ we have $\|f\|_{\Phi}=\int_{\Delta}|f(x)| g(x) d \mu$. The function $g(x)$ and the constant $C$ are those of the theorem.

(b) Assume that postulate (iii) (b) holds. Since $\limsup _{u \rightarrow \infty} \Phi(2 u) / \Phi(u)$ $\leqq N$, there is a $u^{\prime}$ such that for $u^{\prime} \leqq u, \phi(2 u) / \Phi(u) \leqq 2 N$. Then for 
$u^{\prime}<u, \Phi(4 u) \leqq(2 N)^{2} \Phi(u)$. With appropriate modifications of the corresponding demonstration in (a) above we easily show that there is a constant $0<M<\infty$ and a value $u_{1}$ such that for $u_{1} \leqq u, \bar{\varphi}(u) / \varphi(u) \leqq M$. Recalling that $\Delta$ is of finite measure, let $v_{1}>0$ be a value such that $\Psi\left(v_{1}\right) \leq 1 / \mu(\Delta)$, then

$$
\begin{aligned}
\int_{\Delta}|f| \bar{\varphi}(2 C|f|) d \mu & \leqq \int_{\Delta}|f| \bar{\varphi}\left(u_{1}\right) d \mu+M \int_{\Delta}|f| \varphi(C|f|) d \mu \\
& \leqq\left[\begin{array}{c}
\bar{\varphi}\left(u_{1}\right)+M \\
v_{1}
\end{array}\right]\|f\|_{\Phi}
\end{aligned}
$$

since $\varphi(C|f(x)|) \leqq g(x)$ and by Fatou's lemma

$$
\int_{\Delta} \Psi(g) d \mu=\int_{\Delta} \liminf \Psi\left(g_{n}\right) d \mu \leqq \liminf \int_{\Delta} \Psi\left(g_{n}\right) d \mu=1 .
$$

By Young's inequality

$$
\begin{array}{r}
\int_{\Delta} \Psi(\bar{\varphi}(2 C|f|)) d \mu=2 C \int_{\Delta}|f| \bar{\varphi}(2 C|f|) d \mu-\int_{\Delta} \Phi(2 C|f|) d \mu \\
\leqq 2 C \int_{\Delta}|f| \bar{\varphi}(2 C|f|) d \mu \leqq 2 C\left[\frac{\bar{\varphi}\left(u_{1}\right)}{v_{1}}+M\right]\|f\|_{\Phi}<\infty .
\end{array}
$$

But $\bar{\varphi}(2 C|f(x)|) \geqq g_{n}(x) \geqq g(x)$ for all $n$ sufficiently large, so that by Lebesgue's theorem and the monotone property of $\Psi(v)$

$$
\int_{\Delta} \Psi(g) d \mu=\int_{\Delta} \liminf \Psi\left(g_{n}\right) d \mu=\liminf \int_{\Delta} \Psi\left(g_{n}\right) d \mu=1 .
$$

The remainder of the proof is as in (a) above. The constant $C$ and the function $g(x)$ are those of the theorem.

The above theorem may be generalized in several ways. The author has secceeded in obtaining a number of analogous conclusions [8] when the function $\psi(v)$ is discontinuous and when the hypotheses relative to the function $\Phi(u)$ do not hold. It is interesting to observe that for spaces in which conditions (iii) (a) or (iii) (b) do not apply, there is always an element $f$ of the space for which the norm is not attained; that is to say, there is no function $h(x) \geqq 0$ such that $\|f\|_{\Phi}=\int_{\Delta}|f| h d \mu$ with $\int_{\Delta} \Psi(h) d \mu=1$. In this case, however, there is a constant $0<C$ such that

$$
\int_{\Delta} \Psi(\bar{\varphi}(C|f|)) d \mu=1-a,
$$

where $0<a<1$ is a constant; for any larger constant $D>C$ the inte- 
gral $\int_{\Delta} \Psi(\varphi(D|f|) d \mu$ is infinite. It is further remarkable that in this case

$$
\|f\|_{\Phi}=\int_{\Delta}|f| \bar{\varphi}(C|f|) d \mu+a C^{-1} .
$$

The proofs and complete statements of these propositions will not be presented since they are not essential to the discussions relating to convexity. Theorem 4 admits an obvious generalization not only to spaces which satisfy the postulates of Theorem 6, but to the more general case when only the first of these conditions holds. The problem of determining the constant $C$ which appears in all of these theorems in terms of elementary properties of $f(x)$ has hot met with a suitable and satisfying solution despite the author's attempts to find one.

We proceed now to a consideration of the necessary and sufficient conditions for uniform convexity of Orlicz spaces. It was remarked in the introduction that every uniformly convex space is strictly convex but that the converse statement need not be true; therefore, it is clear that any necessary condition for strict convexity must be also a necessary condition for uniform convexity. Thus by Theorems 1 and 2 we must assume at least that $\Psi(v)$ is continuous in the extended sense and $\psi(v)$ is continuous in the extended sense. For a similar reason, the following theorems furnish us with further necessary conditions.

\section{THEOREM 7. [5] Every uniformly convex space is reflexive.}

THEOREM 8. [6] Necessary and sufficient conditions that an Orlicz space be reflexive are that there exist a constant $0<N<\infty$, such that

(a) $\Phi(2 u) / \Phi(u) \leqq N$ and $\Psi(2 v) / \Psi(v) \leqq N, \quad(0<u, 0<v)$ when $\Delta$ is of infinite measure;

(b) $\quad \limsup _{u \rightarrow \infty} \Phi(2 u) / \Phi(u) \leqq N$ and $\limsup _{u \rightarrow \infty} \Psi(2 v) / \Psi(v) \leqq N$ when $\triangle$ is of finite measure.

The conditions implied in Theorems 1, 2 and 8 must be supplemented with an additional necessary condition in order to insure uniform convexity. This is expressed in the next theorem.

THEOREM 9. A necessary condition that $L_{\Phi}$ should be uniformly convex is that for every constant $0<a<\infty$ there is a constant $1<K_{a}<\infty$ such that (a) when $\Delta$ is of infinite measure then $\varphi(u+a u) / \varphi(u)>K_{a}$, $(0<u)$; and (b) when $\Delta$ is of finite measure then $\liminf _{u \rightarrow \infty} \varphi(u+a u) / \varphi(u)$ $>K_{a}$.

Proof. By Theorems 1, 2 and 8 and our above remarks we may 
and shall assume that $\Psi(v)$ and $\psi(v)$ are continuous in the extended sense and that $\lim \sup \Phi(2 u) / \Phi(u) \leqq N$ and $\lim \sup \Psi(2 v) / \Psi(v) \leqq N$ for some constant $0<N<\infty$. We see then that $\psi(v) \rightarrow \infty$ for if $\sup \psi(v) \leqq A$, $0<A<\infty$ then $\varphi(u)=\infty, A<u$ so that $\Phi(2 u)=\int_{0}^{2 u} \varphi(\bar{u}) d \bar{u}=\infty$ for $A / 2<u$ which contradicts $\lim \sup \Phi(2 u) / \Phi(u) \leqq N$. Similarly the condition $\lim \sup \Psi(2 v) / \Psi(v) \leqq N$ implies that $\varphi(v) \rightarrow \infty$.

Suppose there were a value $0<a<\infty$ and a sequence $u_{n}$ such that alternatively according to the respective hypotheses

$$
\begin{gathered}
\frac{\varphi\left(u_{n}+a u_{n}\right)}{\varphi\left(u_{n}\right)} \rightarrow 1 \\
\liminf _{u_{n} \rightarrow \infty} \frac{\varphi\left(u_{n}+a u_{n}\right)}{\varphi\left(u_{n}\right)}=1 .
\end{gathered}
$$

There is then a sequence of pairs: $\left\{v_{n}=\varphi\left(u_{n}\right), \bar{v}_{n}=\varphi\left(u_{n}+a u_{n}\right)\right\}$ such that $\bar{v}_{n} / v_{n} \rightarrow 1$. Let $\lambda_{n}=1 /\left(\Psi\left(v_{n}\right)+\Psi\left(\bar{v}_{n}\right)\right)$ and define $w_{n}$ by $2 \Psi\left(w_{n}\right)=1 / \lambda_{n}$; then $\bar{v}_{n} \geqq w_{n} \geqq v_{n}$ and $\bar{v}_{n} / w_{n} \rightarrow 1, v_{n} / w_{n} \rightarrow 1$. We remark that in the second case $u_{n} \rightarrow \infty$ so that $v_{n} \rightarrow \infty$ and ultimately $\lambda_{n}<\mu(\Delta) / 2$. Determine sets: $A_{n}, B_{n}$ of positive measure such that $A_{n} \cap B_{n}=0, \mu\left(A_{n}\right)=\mu\left(B_{n}\right)=\mu_{n}$ $=\min \left[\mu(\Delta) / 2, \lambda_{n}\right] ;$ and define functions $f_{n}^{\prime}(x), f_{n}^{\prime \prime}(x)$ respectively as

$$
\begin{gathered}
f^{\prime}(x)=\left\{\begin{array}{lll}
\frac{(1+a)}{\left[(1+a) \bar{v}_{n}+v_{n}\right] \mu_{n}} & \text { on } A_{n}, \\
\frac{1}{\left[(1+a) \bar{v}_{n}+v_{n}\right] \mu_{n}} & \text { on } B_{n}, \\
0 & \text { on }\left(A_{n} \cup B_{n}\right)^{\prime}
\end{array}\right. \\
f^{\prime \prime}(x)=\left\{\begin{array}{lll}
\frac{1}{\left[(1+a) \bar{v}_{n}+v_{n}\right] \mu_{n}} & \text { on } A_{n}, \\
\frac{(1+a)}{\left[(1+a) \bar{v}_{n}+v_{n}\right] \mu_{n}} & \text { on } B_{n}, \\
0 & \text { on }\left(A_{n} \cup B_{n}\right)^{\prime} .
\end{array}\right.
\end{gathered}
$$

With $C_{n}^{\prime}=C_{n}^{\prime \prime}=\left[(1+a) \bar{v}_{n}+v_{n}\right] \mu_{n} u_{n}$ we see: $\psi\left(g_{n}^{\prime}\right)=C_{n}^{\prime} f_{n}^{\prime}, \psi\left(g_{n}^{\prime \prime}\right)=C_{n} f_{n}^{\prime \prime}$ where

$$
g_{n}^{\prime}(x)=\left\{\begin{array}{lll}
\bar{v}_{n} & \text { on } & A_{n} \\
v_{n} & \text { on } & B_{n} \\
0 & \text { on } & \left(A_{n} \cup B_{n}\right)^{\prime}
\end{array} \quad g_{n}^{\prime \prime}(x)=\left\{\begin{array}{lll}
v_{n} & \text { on } & A_{n} \\
\bar{v}_{n} & \text { on } & B_{n} \\
0 & \text { on } & \left(A_{n} \cup B_{n}\right)^{\prime}
\end{array}\right.\right.
$$

and for all $n$ sufficiently large so that $\lambda_{n}=\mu_{n}$ we have 


$$
\begin{aligned}
& \int_{\Delta} \Psi\left(g_{n}^{\prime}\right) d \mu=\lambda_{n}\left(\Psi\left(v_{n}\right)+\Psi\left(\bar{v}_{n}\right)\right)=1, \\
& \int_{\Delta} \Psi\left(g_{n}^{\prime \prime}\right) d \mu=\lambda_{n}\left(\Psi\left(v_{n}\right)+\Psi\left(\bar{v}_{n}\right)\right)=1 .
\end{aligned}
$$

Thus, by Theorem 6

$$
\begin{gathered}
\left\|f_{n}^{\prime}\right\|_{\Phi}=\int_{\Delta} f_{n}^{\prime} g_{n}^{\prime} d \mu=\frac{(1+a) \bar{v}_{n}+v_{n}}{(1+a) \bar{v}_{n}+v_{n}}=\frac{\mu_{n}}{\mu_{n}}=1 \\
\left\|f_{n}^{\prime \prime}\right\|_{\Phi}=\int_{\Delta} f_{n}^{\prime \prime} g_{n}^{\prime \prime} d \mu=\frac{(1+a) \bar{v}_{n}+v_{n}}{(1+a) \bar{v}_{n}+v_{n}}=\frac{\mu_{n}}{\mu_{n}}=1 .
\end{gathered}
$$

Now

$$
\frac{f_{n}^{\prime}(x)+f_{n}^{\prime \prime}(x)}{2}=\left\{\begin{array}{lll}
\frac{(1+a / 2)}{\left[(1+a) \bar{v}_{n}+v_{n}\right] \mu_{n}} & \text { on } & A_{n} \cup B_{n} \\
0 & \text { on } & \left(A_{n} \cup B_{n}\right)^{\prime}
\end{array}\right.
$$

so that by Lemma 1 and Theorem 6

$$
\left\|\frac{f_{n}^{\prime}+f_{n}^{\prime \prime}}{2}\right\|_{\Phi}=\frac{(1+a / 2) w_{n}}{\left[(1+a) \bar{v}_{n}+v_{n}\right]} \cdot \frac{2 \lambda_{n}}{\lambda_{n}} \rightarrow 1
$$

since $\bar{v}_{n} / w_{n} \rightarrow 1$ and $v_{n} / w_{n} \rightarrow 1$. Again

$$
\left|f_{n}^{\prime}(x)-f_{n}^{\prime \prime}(x)\right|=\left\{\begin{array}{lll}
\frac{a}{\left[(1+a) \bar{v}_{n}+v_{n}\right]} \cdot \frac{1}{\lambda_{n}} & \text { on } A_{n} \cup B_{n} \\
0 & & \text { on }\left(A_{n} \cup B_{n}\right)^{\prime}
\end{array}\right.
$$

so that

$$
\left\|f_{n}^{\prime}-f_{n}^{\prime \prime}\right\|_{\Phi}=\frac{a}{(1+a / 2)}\left\|\frac{f_{n}^{\prime}+f_{n}^{\prime \prime}}{2}\right\|_{\Phi} \rightarrow \frac{a}{1+a / 2}>0
$$

and $L_{\Phi}$ is not uniformly convex.

Lemma 3. Let $0<\varepsilon<1 / 4$ and $1<K_{\varepsilon}<T<\infty, 0<b$ be constants such that alternatively

$$
\begin{array}{ll}
K_{\varepsilon}<\frac{\varphi((1-\varepsilon) u)}{\varphi\left((1-\varepsilon)^{2} u\right)}<T, & (0<u), \\
K_{\varepsilon}<\frac{\varphi((1-\varepsilon) u)}{\varphi\left((1-\varepsilon)^{2} u\right)}<T, & (b<u),
\end{array}
$$

then there is a constant $0<L_{\varepsilon}$ such that 


$$
\Psi\left(v^{\prime}\right) \geq \Psi(v)+\psi^{\prime}(v)\left(v^{\prime}-v\right)+L_{\varepsilon} \Phi\left(\left|u^{\prime}-u\right|\right)
$$

when respectively

$$
\begin{gathered}
\left.\left|u^{\prime}-u\right| \geq \begin{array}{c}
\left(2 \varepsilon-\varepsilon^{2}\right) \\
(1-\varepsilon)^{2}
\end{array}\right)>0 \\
\left|u^{\prime}-u\right| \geq \max \left[\mathrm{b}, \begin{array}{c}
\left(2 \varepsilon-\varepsilon^{2}\right) \\
(1-\varepsilon)^{2}
\end{array}\right]
\end{gathered}
$$

where $(u, v),\left(u^{\prime}, v^{\prime}\right)$ are related by either $v=\varphi(u)$ or $u=\psi(v)$ and $v^{\prime}=\varphi\left(u^{\prime}\right)$ or $u^{\prime}=\psi\left(v^{\prime}\right)$.

Proof. Assume $u^{\prime} \geqq u$ and consider the first diagram

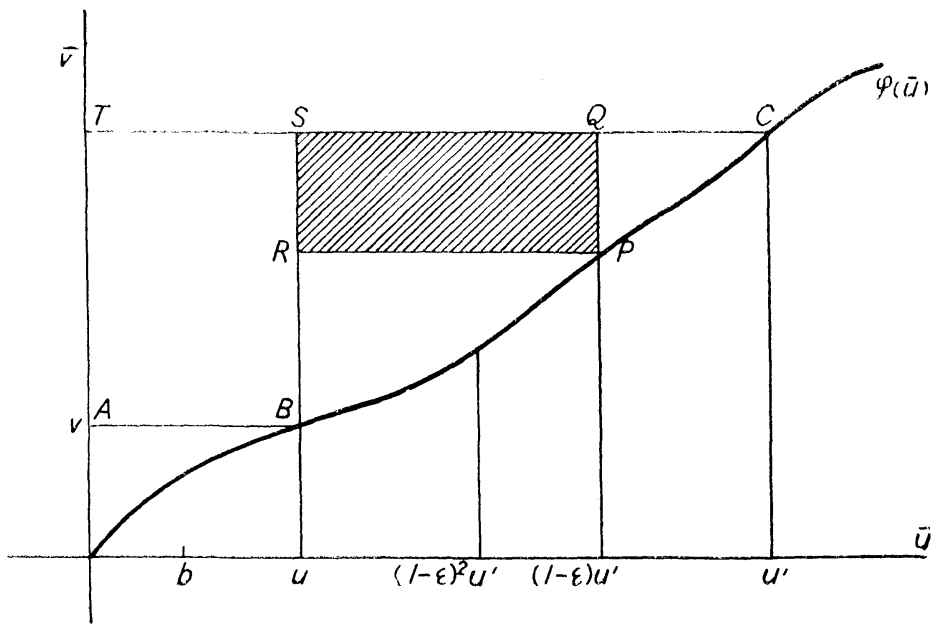

We note first
(a) $(1-\varepsilon)^{2} u^{\prime} \geq u>0$;
(b) $(1-\varepsilon)^{2} u^{\prime} \geq u \geqq b$

according to the respective hypotheses. Since $\varphi(u)$ is a monotone nondecreasing function we find from the definition of $\Psi(v)$

$$
\begin{aligned}
\Psi\left(v^{\prime}\right)-\Psi(v) & =\operatorname{Area}(O C T)-\operatorname{Area}(O B A) \\
& \geq \operatorname{Area}(A B S T)+\operatorname{Area}(P Q R S)
\end{aligned}
$$

so that:

$$
\Psi\left(v^{\prime}\right) \geq \Psi(v)+\psi^{\prime}(v)\left(v^{\prime}-v\right)+\overline{Q P} \cdot \overline{P R}
$$

Observing that respectively

$$
\begin{gathered}
u^{\prime} \\
(1-\varepsilon)
\end{gathered}>u^{\prime} \geq u>0,
$$


(b)

$$
\underset{(1-\varepsilon)}{u^{\prime}}>u^{\prime} \geqq u>b
$$

by corresponding hypotheses with $u^{\prime} /(1-\varepsilon)$ instead of $u$, we see that $\varphi\left((1-\varepsilon) u^{\prime}\right) \leqq\left(1 / K_{\varepsilon}\right) \varphi\left(u^{\prime}\right)$. Thus

$$
\overline{Q P}=\varphi\left(u^{\prime}\right)-\varphi\left((1-\varepsilon) u^{\prime}\right) \geq\left(1-\frac{1}{K_{\varepsilon}}\right) \varphi\left(u^{\prime}\right) .
$$

Also

$$
\overline{P R}=(1-\varepsilon) u^{\prime}-u \geqq\left[(1-\varepsilon)-(1-\varepsilon)^{2}\right] u^{\prime}=\varepsilon(1-\varepsilon) u^{\prime} .
$$

Hence

$$
\begin{aligned}
& \overline{Q P} \cdot \overline{P R} \geqq\left(1-\begin{array}{c}
1 \\
K_{\varepsilon}
\end{array}\right) \varepsilon(1-\varepsilon) u^{\prime} \varphi\left(u^{\prime}\right) \\
& \quad \geq\left(1-\begin{array}{c}
1 \\
K_{\varepsilon}
\end{array}\right) \varepsilon(1-\varepsilon) \Phi\left(u^{\prime}\right) \geqq\left(1-\frac{1}{K_{\varepsilon}}\right) \varepsilon(1-\varepsilon) \Phi\left(\left|u^{\prime}-u\right|\right) .
\end{aligned}
$$

Thus with $P_{\varepsilon}=\left(1-1 / K_{\varepsilon}\right) \varepsilon(1-\varepsilon)>0$ we have

$$
\Psi\left(v^{\prime}\right) \geq \Psi(v)+\psi(v)\left(v^{\prime}-v\right)+P_{\mathrm{a}} \phi\left(\left|u^{\prime}-u\right|\right) .
$$

Assume $u^{\prime}<u$ and consider the second diagram.

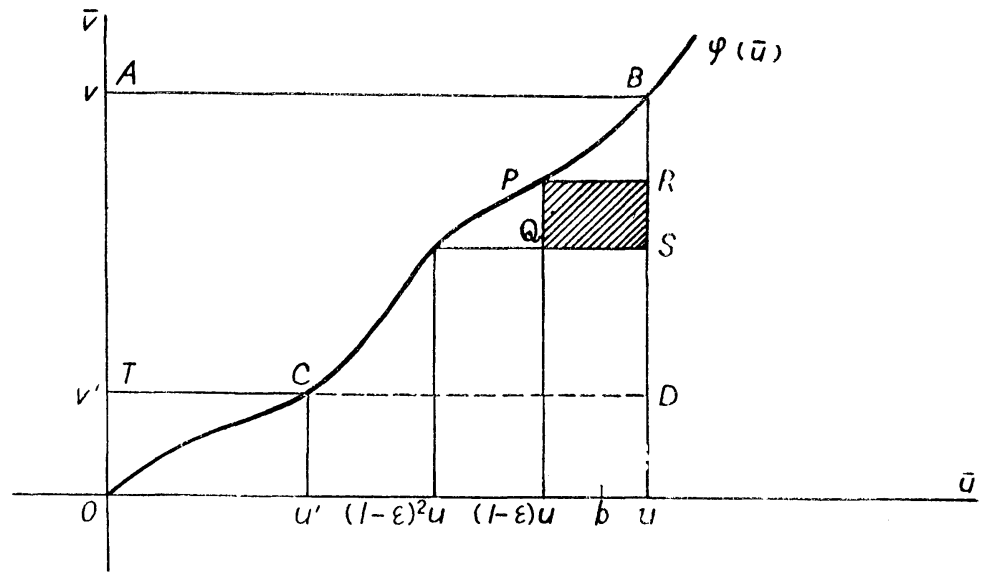

We note first that

$$
u-u^{\prime} \geq \underset{(1-\varepsilon)^{2}}{\left(2 \varepsilon-\varepsilon^{2}\right) u} \geq\left(2 \varepsilon-\varepsilon^{2}\right) u
$$

so that $(1-\varepsilon)^{2} u \geqq u^{\prime}$. Since $\varphi(u)$ is monotone nondecreasing, from the 
definition of $\Psi(v)$ we find:

$$
\begin{aligned}
\Psi(v)-\Psi\left(v^{\prime}\right) & =\text { Area }(O B A)-\text { Area }(O C T) \\
& \leqq \text { Area }(A B D T)-\text { Area }(P Q R S)
\end{aligned}
$$

so that

$$
\begin{aligned}
\Psi\left(v^{\prime}\right) & \geq \Psi(v)-\operatorname{Area}(A B D T)+\text { Area }(P Q R S) \\
& =\Psi(v)+\psi\left(v^{\prime}\right)\left(v^{\prime}-v\right)+\overline{P Q} \cdot \overline{R P} .
\end{aligned}
$$

But

$$
\begin{aligned}
& \overline{P Q}=\varphi((1-\varepsilon) u)-\varphi\left((1-\varepsilon)^{2} u\right) \\
& \geqq\left(1-\frac{1}{K_{\varepsilon}}\right) \varphi((1-\varepsilon) u) \geqq\left(1-\frac{1}{K_{\varepsilon}}\right) \frac{1}{T} \varphi(u)
\end{aligned}
$$

where, if we are considering the second set of hypotheses, we make use of the fact that $\mathrm{b} \leq u$. Also $\overline{R P}=\varepsilon u$; therefore

$$
\begin{aligned}
\Psi\left(v^{\prime}\right) & \geq \Psi(v)+\psi(v)\left(v^{\prime}-v\right)+\left(1-\frac{1}{K_{\varepsilon}}\right)_{T}^{\varepsilon} u \varphi(u) \\
& \geq \Psi(v)+\psi(v)\left(v^{\prime}-v\right)+\left(1-\frac{1}{K_{\varepsilon}}\right)_{T}^{\varepsilon} \Phi(u) \\
& \geq \Psi(v)+\psi(v)\left(v^{\prime}-v\right)+Q_{\varepsilon} \Phi\left(\left|u^{\prime}-u\right|\right)
\end{aligned}
$$

where $Q_{\varepsilon}=\left(1-1 / K_{\varepsilon}\right)(\varepsilon / T)>0$.

Taking $L_{\varepsilon}=\min \left(P_{\varepsilon}, Q_{\varepsilon}\right)$ we have the stated result.

THEOREm 10. Let $\psi^{\prime}(v)$ be continuous, $u=\psi^{\prime}(v)$ and $u^{\prime}=\psi^{\prime}\left(v^{\prime}\right)$ and let $0<\varepsilon<1 / 4,1<R_{\varepsilon} \leq N<\infty$ be constants such that alternatively

(a)

$$
\begin{aligned}
& \text { (i ) } \begin{array}{l}
\Phi(2 u) \leq N, \quad(0<u) \\
\end{array}(u) \leq N(u) \quad, \quad(0<u) \\
& \text { (ii) } \quad R_{\varepsilon}<\begin{array}{c}
\varphi((1-\varepsilon) u) \\
\varphi(1-u)
\end{array} \\
& \text { (iii) }\left|u^{\prime}-u\right|>\frac{\left(2 \varepsilon-\varepsilon^{2}\right)}{(1-\varepsilon)^{\prime \prime}} u>0
\end{aligned}
$$

or

(b)

$$
\text { (i ) } \limsup _{u \rightarrow \infty} \frac{\Phi(2 u)}{\Phi(u)} \leq N \text {, }
$$


(ii) $\quad \limsup _{u \rightarrow \infty} \begin{gathered}\varphi(u) \\ \varphi((1-\varepsilon) u)\end{gathered}>R_{\varepsilon}$,
(iii) $\left|u^{\prime}-u\right| \geqq \max \left[\begin{array}{cc}\left(2 \varepsilon-\varepsilon^{2}\right) & \left(2 \varepsilon-\varepsilon^{2}\right) \\ (1-\varepsilon)^{2} & (1-\varepsilon)^{2}\end{array}\right]$

then there is a constant $L_{\varepsilon}>0$ such that

$$
\Psi\left(v^{\prime}\right) \geq \Psi(v)+\psi(v)\left(v^{\prime}-v\right)+L_{\varepsilon} \Phi\left(\left|u^{\prime}-u\right|\right) .
$$

Proof. (a) By the same reasoning employed in Theorem 6, we may use hypothesis (a) (i) to show that there is a constant $0<M<\infty$ such that $\varphi(2 u) / \varphi(u) \leqq M, 0<u$. Writing $(1-\varepsilon)^{2} u$ for $u$ and noting that $\varphi\left(2(1-\varepsilon)^{2} u\right) \geq \varphi((1-\varepsilon) u), 0<\varepsilon<1 / 4$ we have

$$
M \geq \frac{\varphi\left(2(1-\varepsilon)^{2} u\right)}{\varphi\left((1-\varepsilon)^{2} u\right)} \geq \frac{\varphi((1-\varepsilon) u)}{\varphi\left((1-\varepsilon)^{2} u\right)}, \quad(0<u) .
$$

Again writing $(1-\varepsilon) u$ for $u$ in (ii) we have

$$
R_{\varepsilon}<\frac{\varphi((1-\varepsilon) u)}{\varphi\left((1-\varepsilon)^{2} u\right)}
$$

With $M=T, R_{\varepsilon}=K_{\varepsilon}$ we may apply Lemma 3 to obtain the stated result.

(b) As in the proofs of Theorem 6 we may use (b) (i) to show that there is a constant $0<M<\infty$ such that $\lim \sup \varphi(2 u) / \varphi(u) \leqq M$; this implies that for each $0<\varepsilon<1 / 4$ there is a value $u_{1}<\infty$ such that if $(1-\varepsilon)^{2} u_{1}<u$ then $\varphi(2 u) / \varphi(u) \leqq 2 M$.

Writing $(1-\varepsilon)^{2} u$ for $u$ we see

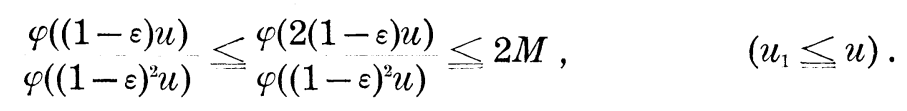

Since $\psi(v)$ is continuous, it follows that if $0<b$ is any constant then $\varphi\left((1-\varepsilon)^{2} b\right)>0$; since $\psi(2 u) / \varphi(u) \leqq 2 M$ when $(1-\varepsilon)^{2} u_{1} \leqq u$ it follows that $\varphi\left(2 u_{1}\right)<\infty$; therefore

$$
\frac{\varphi((1-\varepsilon) u)}{\varphi\left((1-\varepsilon)^{2} u\right)} \leq \frac{\varphi\left(2 u_{1}\right)}{\varphi\left((1-\varepsilon)^{2} b\right)}<\infty \quad\left(b \leqq u \leqslant u_{1}\right) .
$$

Thus with

$$
T=1+\max \left[2 M, \frac{\varphi\left(2 u_{1}\right)}{\varphi\left((1-\varepsilon)^{2} b\right)}\right]
$$

we have 


$$
\frac{\varphi((1-\varepsilon) u)}{\varphi\left((1-\varepsilon)^{2} u\right)}<T
$$

The second hypothesis implies that there is a $u_{2}<\infty$ such that

$$
\frac{\varphi((1-\varepsilon) u)}{\varphi\left((1-\varepsilon)^{2} u\right)}>\frac{R_{\varepsilon}+1}{2}>1
$$

Let $\eta=\left(2 \varepsilon-\varepsilon^{2}\right) /(1-\varepsilon)^{2}$, then $\eta>0$. Let

$$
S=\inf _{\eta<u<u_{2}} \frac{\varphi((1-\varepsilon) u)}{\varphi\left((1-\varepsilon)^{2} u\right)} .
$$

Suppose $S=1$, then there would exist a sequence $\eta \leqq u_{n} \leqq u_{2}$ such that $\varphi\left((1-\varepsilon) u_{n}\right) / \varphi\left((1-\varepsilon)^{2} u_{n}\right) \rightarrow 1$. From this sequence a subsequence $u_{n 1}$ could be extracted which either increases or decreases to a limit $\eta \leqq u^{\prime} \leqq u_{2}$. If $u_{n 1}$ increases to $u^{\prime}$, then the left continuity of $\varphi(u)$ implies that $\varphi\left((1-\varepsilon) u^{\prime}\right) / \varphi\left((1-\varepsilon)^{2} u^{\prime}\right)=1$; while if $u_{n 1}$ decreases to $u^{\prime}$ then the right continuity of $\bar{\varphi}(u)$ implies that $\bar{\varphi}\left((1-\varepsilon) u^{\prime}\right) / \bar{\varphi}\left((1-\varepsilon)^{2} u^{\prime}\right)=1$. In either event this would imply that $\psi(v)$ had a discontinuity at alternatively $v=$ $\varphi\left((1-\varepsilon) u^{\prime}\right)$ or $v=\bar{\varphi}\left((1-\varepsilon) u^{\prime}\right)$, since $\psi(v) \leqq(1-\varepsilon)^{2} u^{\prime}<(1-\varepsilon) u^{\prime} \leqq \bar{\psi}(v)$. Since $\psi^{\prime}(v)$ is continuous by hypothesis, we conclude: $S>1$. If we let $K_{\varepsilon}=\min \left[S,\left(R_{\varepsilon}+1\right) / 2\right], \quad b=\left(2 \varepsilon-\varepsilon^{2}\right) /(1-\varepsilon)^{2}$ and $T$ as above, we see that the hypotheses of Lemma 3 are satisfied and we have established the proposition.

We shall suppress the proofs of the two following lemmas since they may be found readily in the reference cited.

Lemma 4. [10] If $f(x) \in L_{\Phi}$ and $f(x) \neq 0$ on a set of positive measure, then

$$
\int_{\Delta} \Phi\left(\frac{|f(x)|}{\|f\|_{\Phi}}\right) d \mu \leqq 1
$$

Lemma 5. [10] If $f(x) \in L_{\Phi}$ and if there is a constant $0<N<\infty$ such that (a) $\Phi(2 u) / \Phi(u) \leqq N, 0<u$ when $\Delta$ is of infinite measure; or (b) $\limsup _{u \rightarrow \infty} \Phi(2 u) / \Phi(u) \leqq N$ when $\Delta$ is of finite measure, then

$$
\int_{\Delta} \Phi(|f(x)|) d \mu<\infty
$$

Lemma 6. If $\left\{f_{n}(x)\right\}$ is a sequence of elements of $L_{\Phi}$ such that $\int_{\Delta} \Phi\left(\left|f_{n}(x)\right|\right) d \mu \rightarrow 0$ and if there is a constant $0<N<\infty$ such that either (a) $\Phi(2 u) / \Phi(u) \leqq N, 0<u$ when $\Delta$ is of infinite measure; or 
(b) $\limsup _{n \rightarrow \infty} \Phi(2 u) / \Phi(u) \leqslant N$ and also $\psi^{\prime}(v)$ is continuous, when $\Delta$ is of finite measure, then $\left\|f_{n}\right\|_{\Phi} \rightarrow 0$.

Proof. (a) let $p \geq 1$ be any positive integer and choose $n_{p}$ sufficiently small so that $\int_{\Delta} \Phi\left(\left|f_{n}(x)\right|\right) d \mu \leqq 1 / N^{n}$ for all $n_{p} \leqq n$. Then

$$
\int_{\Delta} \Phi\left(2^{\prime \prime}\left|f_{n}\right|\right) d \mu \leq N^{n} \int_{\Delta} \Phi\left(\left|f_{n}\right|\right) d \mu \leq 1
$$

so that if $g_{n}(x) \geq 0$ and $\int_{\Delta} \Psi\left(g_{n}\right) d \mu \leqq 1$ by Young's inequality

$$
\int_{\Delta} 2^{p}\left|f_{n}\right| g_{n} d \mu \leqq \int_{\Delta} \Phi\left(2^{p}\left|f_{n}\right|\right) d \mu+\int_{\Delta} \Psi\left(g_{n}\right) d \mu \leqq 2
$$

so that $\left\|f_{n}\right\|_{\Phi} \leqq 2 / 2^{p},\left(n_{p} \leqq n\right)$. Since $p$ may be chosen arbitrarily large, the proposition is demonstrated.

(b) Since $\limsup \Phi(2 u) / \Phi(u) \leqq N$ it follows that there is a $u^{\prime}<\infty$ such that: $\Phi(2 u) / \Phi(u) \leqq 2 N, u^{\prime} \leqq u$ and $\Phi\left(2 u^{\prime}\right)<\infty$. Since $\psi(v)$ is continuous and $\psi(0)=0$, it follows that $\varphi(u)>0,0<u$ and hence $\Phi(u)>0$, $0<u$; therefore, if $0<u^{\prime \prime} \leqq u^{\prime}$ be any number we see $\Phi(2 u) / \Phi(u) \leqq$ $\Phi\left(2 u^{\prime}\right) / \Phi\left(u^{\prime \prime}\right)<\infty$ when $u^{\prime \prime} \leqq u \leqq u^{\prime}$ so that if $N_{u^{\prime \prime}}=\max \left[2 N, \Phi\left(2 u^{\prime}\right) / \Phi\left(u^{\prime \prime}\right)\right]$ we have $\Phi(2 u) / \Phi(u) \leq N_{u^{\prime \prime}}<\infty$, $u^{\prime \prime}<u$. Let $p \geqq 1$ be any number and choose $0<u^{\prime \prime} \leqq 1 / 2^{n}$; let $S_{n}=E\left[\left|f_{n}(x)\right| \geqq u^{\prime \prime}\right]$. If $g_{n}(x) \geqq 0$ and $\int_{\Delta} \Psi\left(g_{n}\right) d \mu \leqq 1$ then by Young's inequality

$$
\begin{aligned}
\int_{\Delta} 2^{p}\left|f_{n}\right| g_{n} d \mu & \leq \int_{\Delta} \Phi\left(2^{\prime \prime}\left|f_{n}\right|\right) d \mu+\int_{\Delta} \Psi\left(g_{n}\right) d \mu \\
& \varsigma \int_{S_{n}} \Phi\left(2^{\prime \prime}\left|f_{n}\right|\right) d \mu+\int_{S_{n}^{\prime}} \Phi\left(2^{\prime \prime}\left|f_{n}\right|\right) d \mu+1 \\
& \lesssim\left(N_{u^{\prime \prime}}\right)^{\prime \prime} \int_{S_{n}} \Phi\left(\left|f_{n}\right|\right) d \mu+\Phi(1) \mu(\Delta)+1
\end{aligned}
$$

By choosing $n$ sufficiently large, we have $\int_{s_{n}} \Phi\left(\left|f_{n}\right|\right) d \mu \leqq\left(N_{u^{\prime \prime}}\right)^{-1 \prime}$ so that

$$
\left\|f_{n}\right\|_{\Phi}: \frac{2+\Phi(1) \mu(\Delta)}{2^{p}} \cdot
$$

Taking $p$ sufficiently large we see that $\left\|f_{n}\right\|_{\Phi} \rightarrow 0$ since $\mu(\Delta)<\infty$.

Lemma 7. If $\alpha, \beta$ are real, then 


$$
|\alpha-\beta|=|\alpha|+|\beta|-|\alpha+\beta|+|| \alpha|-| \beta||
$$

Proof. If $\alpha \geq \beta \geq 0$ then $|\alpha-\beta|=|| \alpha|-| \beta||$ and $|\alpha|+|\beta|=|\alpha+\beta|$. If $\alpha \geq 0 \geq \beta$ then $|\alpha|+|\beta|=|\alpha-\beta|$ and $|\alpha+\beta|=|| \alpha|-| \beta||$. If $0>\alpha \geq \beta$ then $|\alpha|+|\beta|=|\alpha+\beta|$ and $|\alpha-\beta|=|| \alpha|-| \beta||$. The remaining cases in which $\beta \geq \alpha$ hold by symmetry.

LEMMA 8. If $\eta \leqq 1$ then $\Phi(\gamma u) \leqq \eta \Phi(u)$ and if $\eta \geqq 1$ then $\Phi(\mu u) \geqq$ $\eta \Phi(u)$.

Proof. Since $\varphi(u)$ is monotone nondecreasing if $\eta \leq 1$ we have

$$
\Phi(\eta u)=\int_{0}^{\eta u} \varphi(\bar{u}) d \bar{u} \leqq \eta \int_{0}^{u} \varphi(\bar{u}) d \bar{u}=\eta \Phi(u) .
$$

If $\eta \geq 1$ and $\xi=1 / \eta \leqq 1$ then $\Phi\left(\xi u^{\prime}\right) \leqq \xi \Phi\left(u^{\prime}\right)$; so that, if $\xi u^{\prime}=u$, we have $\eta \Phi(u) \leqq \Phi(\eta u)$.

Lemma 9. (a) If there is a constant $0<N<\infty$ such that $\Phi(2 u) / \Phi(u)$ $\leq N$ then

$$
\Phi\left(u_{1}+u_{2}\right) \leqq N\left[\Phi\left(u_{1}\right)+\Phi\left(u_{2}\right)\right],
$$

for arbitrary $0 \leqq u_{1}, 0 \leqq u_{2}$;

(b) if for each $0<u^{\prime \prime}$ there is a constant $0<N_{u^{\prime \prime}}<\infty$ such that $\Phi(2 u) / \Phi(u) \leqq N_{u^{\prime \prime}}, u^{\prime \prime} \leqq u$, then

$$
\Phi\left(u_{1}+u_{2}\right) \leqq \Phi\left(2 u^{\prime \prime}\right)+N_{u^{\prime \prime}}\left[\Phi\left(u_{1}\right)+\Phi\left(u_{2}\right)\right]
$$

for arbitrary $0 \leqq u_{1}, 0 \leqq u_{2}$.

Proof. (a) Let $u_{3}=\max \left[u_{1}, u_{2}\right]$ so that $u_{1}+u_{2} \leqq 2 u_{3}$. Then

$$
\Phi\left(u_{1}+u_{2}\right) \leqq \Phi\left(2 u_{3}\right) \leqq N \Phi\left(u_{3}\right) \leqq N\left[\Phi\left(u_{1}\right)+\Phi\left(u_{2}\right)\right] .
$$

(b) Let $u_{3}=\max \left[u_{1}, u_{2}\right]$. If $u_{3} \leqq u^{\prime \prime}$, then

$$
\Phi\left(u_{1}+u_{2}\right) \leqq \Phi\left(2 u_{3}\right) \leqq \Phi\left(2 u^{\prime \prime}\right) \text {. }
$$

If $u_{3}>u^{\prime \prime}$ then

$$
\Phi\left(u_{1}+u_{2}\right) \leqq \Phi\left(2 u_{3}\right) \leqq N_{u^{\prime \prime}} \Phi\left(u_{3}\right) \leqq N_{u^{\prime \prime}}\left[\Phi\left(u_{1}\right)+\Phi\left(u_{2}\right)\right] .
$$

Theorem 10. Let $\Psi(v)$ and $\psi(v)$ continuous and let $0<\varepsilon<1 / 4$, $1<R_{\varepsilon} \leqq N<\infty$ be constants such that alternatively

(a) when $\Delta$ is of infinite measure 

(i) $\Phi(2 u) / \Phi(u) \leqq N$,
$(0<u)$
(ii) $R_{\varepsilon}<\frac{\varphi(u)}{\varphi((1-\varepsilon) u)}$,
$(0<u)$

or

(b) when $\Delta$ is of finite measure

$$
\begin{aligned}
& \text { (i) } \limsup _{u \rightarrow \infty} \Phi(2 u) / \Phi(u) \leqq N, \\
& \text { (ii) } \limsup _{u \rightarrow \infty} \frac{\varphi(u)}{\varphi((1-\varepsilon) u)}>R_{\varepsilon}
\end{aligned}
$$

then $L_{\Phi}$ is uniformly convex.

Proof. We first assume that $f_{n}^{\prime}(x) \geqq 0, f_{n}^{\prime \prime}(x) \geqq 0$, that $\left\|f_{n}^{\prime}\right\|_{\Phi}=\left\|f_{n}^{\prime \prime}\right\|_{\Phi}=1$ and that $\frac{1}{2}\left\|f_{n}^{\prime}+f_{n}^{\prime \prime}\right\|_{\Phi} \rightarrow 1$; and we shall prove that $\left\|f_{n}^{\prime}-f_{n}^{\prime \prime}\right\|_{\Phi} \rightarrow 0$.

Let $\eta=\left(2 \varepsilon-\varepsilon^{2}\right) /(1-\varepsilon)^{2}$; we observe that $\lim _{\varepsilon \rightarrow 0} \eta=0$. By Theorem 9 there is a constant $0<L_{\eta}<\infty$ such that, corresponding to the alternative hypotheses, when

$$
\begin{aligned}
& \left|u^{\prime}-u\right| \geq \eta u>0, \\
& \left|u^{\prime}-u\right| \geq \max (\eta, \eta u),
\end{aligned}
$$

then

$$
\Psi\left(v^{\prime}\right) \geq \Psi(v)+\psi(v)\left(v^{\prime}-v\right)+L_{\eta} \Phi\left(\left|u^{\prime}-u\right|\right)
$$

where $u=\psi^{\prime}(v)$ and $u^{\prime}=\psi^{\prime}\left(v^{\prime}\right)$. By Theorem 6 , let $1<D_{n}<\infty, 1<C_{n}^{\prime}<\infty$ be constants, $g_{n}(x) \geqq 0, h^{\prime}(x) \geqq 0$ be functions such that

$$
\begin{array}{lll}
\psi\left(g_{n}(x)\right)=D_{n}\left(\frac{f_{n}^{\prime}(x)+f_{n}^{\prime \prime}(x)}{2}\right), & \int_{\Delta} \Psi\left(g_{n}\right) d \mu=1 \\
\psi\left(h_{n}^{\prime}(x)\right)=C_{n}^{\prime} f_{n}^{\prime}(x), & & \int_{\Delta} \Psi\left(h_{n}^{\prime}\right) d \mu=1 .
\end{array}
$$

Let alternatively

$$
E_{n}(\eta) \equiv E_{x}\left[\left|C_{n}^{\prime} f_{n}^{\prime}(x)-\frac{D_{n}}{2}\left(f_{n}^{\prime}(x)+f_{n}^{\prime \prime}(x)\right)\right| \geq \eta C_{n}^{\prime} f_{n}^{\prime}(x)\right]
$$

$$
E_{n}(\eta) \equiv \underset{x}{E}\left[\left|C_{n}^{\prime} f_{n}^{\prime}(x)-\frac{D_{n}}{2}\left(f_{n}^{\prime}(x)+f_{n}^{\prime \prime}(x)\right)\right| \geqq \max \left[\eta, \eta C_{n}^{\prime} f_{n}^{\prime}(x)\right] .\right.
$$

Write $v^{\prime}=g_{n}(x), v=h_{n}^{\prime}(x)$ in $(*)$ above and integrate over $E_{n}(\eta)$ to obtain 


$$
\begin{aligned}
\int_{E_{n}(\eta)} \Psi\left(g_{n}\right) d \mu \geqq & \int_{E_{n}(\eta)} \Psi\left(h_{n}^{\prime}\right) d \mu+\int_{E_{n}(\eta)} C_{n}^{\prime} f_{n}^{\prime}(x)\left(g_{n}(x)-h_{n}^{\prime}(x)\right) d \mu \\
& +L_{\eta} \int_{E_{n}(\eta)} \Phi\left(\left|C_{n}^{\prime} f_{n}^{\prime}(x)-\frac{D_{n}}{2}\left(f_{n}^{\prime}(x)+f_{n}^{\prime \prime}(x)\right)\right|\right) d \mu .
\end{aligned}
$$

But, by Lemma $2, \Psi\left(v^{\prime}\right) \geq \Psi(v)+\psi(v)\left(v^{\prime}-v\right)$; so that making the same substitutions as before and integrating over $E_{n}^{\prime}(\eta)$ we may assert

$$
\int_{E_{n}^{\prime}(\eta)} \Psi\left(g_{n}\right) d \mu \geqq \int_{E_{n}^{\prime}(\eta)} \Psi\left(h_{n}^{\prime}\right) d \mu+\int_{E_{n}^{\prime}(\eta)} C_{n}^{\prime} f_{n}^{\prime}(x)\left(g_{n}(x)-h_{n}^{\prime}(x)\right) d \mu .
$$

Hence

$$
\begin{aligned}
\int_{\Delta} \Psi\left(g_{n}\right) d \mu \geq & \int_{\Delta} \Psi\left(h_{n}^{\prime}\right) d \mu+C_{n}^{\prime} \int_{\Delta} C_{n}^{\prime} f_{n}^{\prime}(x)\left(g_{n}(x)-h_{n}^{\prime}(x)\right) d \mu \\
& +L_{\eta} \int_{E_{n}(\eta)} \Phi\left(\left|C_{n}^{\prime} f_{n}^{\prime}(x)-\frac{D_{n}}{2}\left(f_{n}^{\prime}(x)+f_{n}^{\prime \prime}(x)\right)\right|\right) d \mu,
\end{aligned}
$$

so that

$$
C_{n}^{\prime} \int_{\Delta} f_{n}^{\prime}(x)\left(h_{n}^{\prime}(x)-g_{n}(x)\right) d \mu \geqq L_{\eta} \int_{{ }^{i}{ }_{n}(\eta)} \Phi\left(\left|C_{n}^{\prime} f_{n}^{\prime}-\frac{D_{n}}{2}\left(f_{n}^{\prime}+f_{n}^{\prime \prime}\right)\right|\right) d \mu .
$$

By Lemma 8 , since $1 \leqslant C_{n}^{\prime}<\infty$ we have

(+) $\quad \int_{\perp} f_{n}^{\prime}(x)\left(h_{n}^{\prime}(x)-g_{n}(x)\right) d \mu \geq L_{\eta} \int_{E_{n}(\eta)} \Phi\left(\left|f_{n}^{\prime}-\frac{D_{n}}{2 C_{n}^{\prime}}\left(f_{n}^{\prime}+f_{n}^{\prime \prime}\right)\right|\right) d \mu$.

Now

$$
\begin{aligned}
\| f_{n}^{\prime}+ & f_{n}^{\prime \prime} \|_{\Phi}=\int_{\Delta}\left(f_{n}^{\prime}(x)+f_{n}^{\prime \prime}(x)\right) g_{n}(x) d \mu \\
& =\int_{\Delta} f_{n}^{\prime}(x) g_{n}(x) d \mu+\int_{\Delta} f_{n}^{\prime \prime}(x) g_{n}(x) d \mu \leq\left\|f_{n}^{\prime}\right\|_{\Phi}+\left\|f_{n}^{\prime \prime}\right\|_{\Phi} .
\end{aligned}
$$

But

$$
\int_{\Delta} f_{n}^{\prime}(x) g_{n}(x) d \mu \leqq \int_{\Delta} f_{n}^{\prime}(x) h_{n}^{\prime}(x) d \mu \leqq\left\|f_{n}^{\prime}\right\|_{\Phi}
$$

and

$$
\int_{\Delta} f_{n}^{\prime \prime}(x) g_{n}(x) d \mu \leq\left\|f_{n}^{\prime \prime}\right\|_{\Phi}
$$

and also

$$
\left\|f_{n}^{\prime}+f_{n}^{\prime \prime}\right\|_{\Phi} \rightarrow\left\|f_{n}^{\prime}\right\|_{\Phi}+\left\|f_{n}^{\prime \prime}\right\|_{\Phi}
$$


so that:

$$
\int_{\perp} f_{n}^{\prime}(x)\left(h_{n}^{\prime}(x)-g_{n}(x)\right) d \mu \rightarrow 0
$$

Thus by $(+)$ since $0<I_{\eta}<\infty$,

$(* *) \quad \int_{{ }^{E}{ }_{n}(n)} \Phi\left(\left|f_{n}^{\prime}-\Gamma_{2 C_{n}}\left(f_{n}^{\prime}+f_{n}^{\prime \prime}\right)\right|\right) d \mu \rightarrow 0$.

on $E_{n}^{\prime}(\eta)$ alternatively

(a)

$$
\left|f_{n}^{\prime}(x)-\frac{D_{n}}{2 C_{n}^{\prime \prime}}\left(f_{n}^{\prime \prime}(x)+f_{n}^{\prime \prime}(x)\right)\right| \leqq \eta f_{n}^{\prime}(x) ;
$$

(b) $\left|f_{n}^{\prime}(x)-I_{n}^{\prime \prime}\left(f_{n}^{\prime}(x)+f_{n}^{\prime \prime}(x)\right)\right| \leqq \max \left[\begin{array}{c}\eta \\ C_{n}^{\prime \prime}\end{array}, \eta f_{n}^{\prime}(x)\right] \leqq \max \left[\eta, \eta f_{n}^{\prime}(x)\right]$

so that, since $\eta \leqslant 1$, by Lemma 4 and 8 we have alternatively as $\varepsilon \rightarrow 0$

(a)

$$
\begin{aligned}
& \int_{E_{n}^{\prime}(\eta)} \Phi\left(|f_{n}^{\prime}-\underbrace{D D_{n}}_{2 C_{n}^{\prime}}\left(f_{n}^{\prime}+f_{n}^{\prime \prime}\right)|\right) d \mu \leqq \int_{E_{n}^{\prime}(\eta)} \Phi\left(\eta f_{n}^{\prime}\right) d \mu \\
& \leq \eta \int_{\Gamma_{n}^{\prime}(\eta)} \phi\left(f_{n}^{\prime}\right) d \mu \leqq \eta \int_{\Delta} \Phi\left(f_{n}^{\prime}\right) d \mu \leqq \eta \rightarrow 0
\end{aligned}
$$

(b)

$$
\begin{aligned}
\int_{E_{n}^{\prime}(\eta)} \Phi\left(\mid f_{n}^{\prime}\right. & \left.-D_{2 C_{n}^{\prime}}\left(f_{n}^{\prime}+f_{n}^{\prime \prime}\right) \mid\right) d \mu \leqq \int_{E_{n}^{\prime}(\eta)} \Phi(\eta) d \mu \\
& +\int_{E_{n}^{\prime}(\eta)} \Phi\left(\eta f_{n}^{\prime}\right) d \mu \lesssim \Phi(\eta) \mu(\Delta)+\int_{\Delta} \Phi\left(\eta f_{n}^{\prime}\right) d \mu \\
& \leq \Phi(\eta) \mu(\Delta)+\eta \int_{\Delta} \Phi\left(f_{n}^{\prime}\right) d \mu \leq \Phi(\eta) \mu(\Delta)+\eta \rightarrow 0
\end{aligned}
$$

since $\mu(\Delta)$ is finite. Combining these results with $(* *)$ we see that

$$
\int_{\Delta} \Phi\left(\left|f_{n}^{\prime}-\underset{2 C_{n}^{\prime \prime}}{D_{n}}\left(f_{n}^{\prime}+f_{n}^{\prime \prime}\right)\right|\right) d \mu \rightarrow 0 \text {. }
$$

Thus by Lemma 6

$$
\left\|f_{n}^{\prime}-\frac{D_{n}}{2 C_{n}^{\prime \prime}}\left(f_{n}^{\prime \prime}+f_{n}^{\prime \prime}\right)\right\|_{\Phi} \rightarrow 0
$$

and this implies in turn that

$$
\begin{gathered}
D_{n} \\
C_{n}^{\prime}
\end{gathered}\left\|\frac{f_{n}^{\prime}+f_{n}^{\prime \prime}}{2}\right\|_{\Phi} \rightarrow\left\|f_{n}^{\prime}\right\|_{\Phi}
$$


But $\frac{1}{2}\left\|f_{n}^{\prime}+f_{n}^{\prime \prime}\right\|_{\Phi} \rightarrow 1=\left\|f_{n}^{\prime}\right\|_{\Phi}$ so that $D_{n} / C_{n}^{\prime} \rightarrow 1$. It then follows that

$$
\left\|f_{n}^{\prime}-\left(\frac{f_{n}^{\prime}+f_{n}^{\prime \prime}}{2}\right)\right\|_{\Phi} \rightarrow 0
$$

from which we have immediately that

$$
\left\|f_{n}^{\prime}-f_{n}^{\prime \prime}\right\|_{\Phi} \rightarrow 0 \text {. }
$$

We now prove the theorem for the general case when the functions $f_{n}^{\prime}(x), f_{n}^{\prime \prime}(x)$ are not necessarily positive. We use the equivalent definition of uniform convexity which has been noted in the introduction. Let $\left\|f_{n}^{\prime}\right\|_{\Phi}=\left\|f_{n}^{\prime \prime}\right\|_{\Phi}=1$ and suppose $\left\|f_{n}^{\prime}+f_{n}^{\prime \prime}\right\|_{\Phi} \rightarrow 2$. We define

$$
\begin{aligned}
& F_{n}^{\prime}(x)=\left\{\begin{array}{cl}
\left|f_{n}^{\prime}(x)\right| & \text { if }\left(f_{n}^{\prime}(x)+f_{n}^{\prime \prime}(x)\right) \text { has the sign of } f^{\prime}(x) \\
0 & \text { otherwise ; }
\end{array}\right. \\
& F_{n}^{\prime \prime}(x)=\left\{\begin{array}{cl}
\left|f_{n}^{\prime \prime}(x)\right| & \text { if }\left(f_{n}^{\prime}(x)+f_{n}^{\prime \prime}(x)\right) \text { has the sign of } f_{n}^{\prime \prime}(x), \\
0 & \text { otherwise }
\end{array}\right.
\end{aligned}
$$

Clearly

$$
\begin{gathered}
0 \leqq F_{n}^{\prime}(x) \leqq\left|f_{n}^{\prime}(x)\right|, \quad 0 \leqq F_{n}^{\prime \prime}(x) \leqq\left|f_{n}^{\prime \prime}(x)\right|, \\
F_{n}^{\prime}(x)+F_{n}^{\prime \prime}(x) \geqq\left|f_{n}^{\prime}(x)+f_{n}^{\prime \prime}(x)\right|
\end{gathered}
$$

and

$$
2\left|F_{n}^{\prime}(x)-F_{n}^{\prime \prime}(x)\right| \geq\left|f_{n}^{\prime}(x)-f_{n}^{\prime \prime}(x)\right|,
$$

so that $\left\|F_{n}^{\prime}\right\|_{\Phi} \leqq 1, \quad\left\|F_{n}^{\prime \prime}\right\|_{\Phi} \leqq 1, \quad \lim \inf \left\|F_{n}^{\prime}+F_{n}^{\prime \prime}\right\|_{\Phi} \geqq 2$ and $\left\|f_{n}^{\prime \prime}-f_{n}^{\prime \prime}\right\| \leqq$ $2\left\|F_{n}^{\prime}-F_{n}^{\prime \prime}\right\|_{\Phi}$. Our result for positive functions applied to $F_{n}^{\prime}(x)$ and $F_{n}^{\prime \prime}(x)$ now gives $\left\|f_{n}^{\prime}-f_{n}^{\prime \prime}\right\|_{\Phi} \rightarrow 0$ and $L_{\Phi}$ is uniformly convex.

THEOREM 11. Necessary and sufficient conditions that $L_{\Phi}$ be uniformly convex are

(a) in case $\Delta$ is of infinite measure

(i ) $\Psi(v)$ is continuous,

(ii) $\psi(v)$ is continuons,

(iii) there is a constant $0<N<\infty$ such that $\Phi(2 u) / \Phi(u) \leqq N$, $\Psi(2 v) / \Psi(v) \leqq N,(0<u, 0<v)$.

(iv) for each constant $0<\varepsilon<1 / 4$ there is a constant $1<R_{\varepsilon}<\infty$ such that $\varphi(u) / \varphi((1-\varepsilon) u)>R_{\varepsilon},(0<u)$;

$r$ :

(b) in case $\Delta$ is of finite measure

(i) $\Psi(v)$ is continuons,

(ii) $\psi(v)$ is continuous,

(iii) there is a constant $0<N<\infty$ such that 
$\limsup _{u \rightarrow \infty} \Phi(2 u) / \Phi(u) \leqq N, \quad$ and $\quad \limsup _{v \rightarrow \infty} \Psi(2 v) / \Psi(v) \leqq N$

(iv) for each constant $0<\varepsilon<1 / 4$ there is a constant $1<R_{\varepsilon}<\infty$ such that $\liminf _{u \rightarrow \infty} \varphi(u) / \varphi((1-\varepsilon) u)>R_{\varepsilon}$.

Proof. The theorem is simply a summary of the results of Theorems $1,2,7,8$ and 9 and of Theorem 10 .

It is interesting to remark (a) that the condition $\varphi((1+\varepsilon) u) \mid \varphi(u)>$ $R_{\varepsilon}>1$ implies that $\Psi(2 v) / \Psi(v) \leqq N$ for some constant $0<N<\infty$, and (b) that the condition $\liminf \varphi((1+\varepsilon) u) / \varphi(u)>R_{\varepsilon}>1$ implies that $\lim \sup \Psi(2 v) / \Psi(v) \leqq N$ for some constant $0<N<\infty$; but the implications converse to (a) and (b) are untrue. To prove the direct statement we choose an integer $0<p$ such that $\left(\left(R_{\varepsilon}+1\right) / 2\right)^{p}>2$. Now, respectively (a) for all $0<u$,

$$
\frac{\varphi((1+\varepsilon) u)}{\varphi(u)}>\left(\begin{array}{c}
R_{\varepsilon}+1 \\
2
\end{array}\right)
$$

and (b) there is a value $0<u_{\varepsilon}$ such that if $u_{\varepsilon} \leqq u$, then

$$
\frac{\varphi((1+\varepsilon) u)}{\varphi(u)}>\left(\begin{array}{c}
R_{\varepsilon}+1 \\
2
\end{array}\right)
$$

Then if (a) $0<u$, (b) $u_{\varepsilon}<u$, we see that

$$
\varphi\left((1+\varepsilon)^{n} u\right) \geqq\left(\begin{array}{c}
R_{\varepsilon}+1 \\
2
\end{array}\right)^{p} \varphi(u) \geqq 2 \varphi(u) .
$$

Letting $v=\varphi(u)$ we have $(1+\varepsilon)^{n} \psi(v) \geqq \psi(2 v)$ when alternatively:

(a) $0<v$,

(b) $v_{\varepsilon}<v$ where $v_{\varepsilon}=\varphi\left(u_{\varepsilon}\right)$. But then

$$
(1+\varepsilon)^{n} \Psi(v)=(1+\varepsilon)^{n} \int_{0}^{v} \psi(\bar{v}) d \bar{v} \geqq \int_{0}^{v} \psi(2 \bar{v}) d v \geqq \frac{1}{2} \Psi(2 v)
$$

where $0<v$,

$$
\begin{aligned}
(1+\varepsilon)^{n} \Psi(v) & =(1+\varepsilon)^{n} \int_{v_{\varepsilon}}^{v} \psi(\bar{v}) d \bar{v}+(1+\varepsilon)^{n} \Psi\left(v_{\varepsilon}\right) \\
& \geqq \int_{v_{\varepsilon}}^{v} \psi(2 \bar{v}) d \bar{v}+(1+\varepsilon)^{n} \Psi\left(v_{\varepsilon}\right)>\frac{1}{2} \Psi(2 v)-\frac{1}{2} \Psi\left(2 v_{\varepsilon}\right)
\end{aligned}
$$

where $v_{\varepsilon} \leqq v$, and since $\Psi\left(2 v_{\varepsilon}\right)<\infty$ and $\Psi(v) \rightarrow \infty$ we see that $\limsup _{v \rightarrow \infty} \Psi(2 v) / \Psi(v) \leqq 2(1+\varepsilon)^{n}<\infty$. To prove the converse construct the 
following function. Let $u_{1}=0, v_{1}=0, u_{n}=2^{n}, v_{n}=2^{n}, u_{n}^{\prime}=(1+\varepsilon) u_{n}, v_{n}^{\prime}=$ $\left(2^{n}+\frac{1}{2}\right) ;(n=2,3, \cdots)$. Join the points $\left(u_{1} v_{1}\right)$ to $\left(u_{2} v_{2}\right) ;\left(u_{n} v_{n}\right)$ to $\left(u_{n}^{\prime} v_{n}^{\prime}\right)$; $\left(u_{n}^{\prime}, v_{n}^{\prime}\right)$ to $\left(u_{n+1}, u_{n+1}\right)$ each by straight line segments and let this function be $\varphi(u)$. Then

$$
\frac{\varphi\left((1+\varepsilon) u_{n}\right)}{\varphi\left(u_{n}\right)}=\frac{\varphi\left(u_{n}^{\prime}\right)}{\varphi\left(u_{n}\right)}=\frac{v_{n}^{\prime}}{v_{n}}=\frac{2^{n}+\frac{1}{2}}{2^{n}} \rightarrow 1
$$

while $\psi(2 v) \leqq 4 \psi(v),(0<v)$ and therefore $\Psi(2 v) / \Psi(v) \leqq 8,(0<v)$. It is also clear that condition (i) is implied by the condition $\limsup _{v \rightarrow \infty} \Psi(2 v) / \Psi(v)$ $\leqq N$ and consequently by (iv). Thus, if we wished to do so, we might delete any statement relative to the function $\Psi(v)$ from Theorem 11. It is true, however, that the remaining conditions are independent for none of them is implied by any combination of the other hypotheses.

\section{REFERENCES}

1. J. A. Clarkson, Uniformly convex spaces, Trans. Amer. Math. Soc., 40 (1936), 396-414.

2. M. M. Day, Uniform convexity in factor and conjugate spaces, Ann. of Math., 45 (1944), 375-385.

3. - Uniform convexity, Bull. Amer. Math. Soc., 49 (1943), 745-750.

4. I. Halperin, Uniform convexity in function spaces, Duke Math. J., 21 (1954), 195-204.

5. S. Kakutani, Weak tapology of Banach spaces, Proc. Imperial Acad. Japan, 15 (1939), 169-173.

6. G. Lorentz, Properties of Banach lattices, Unpublished manuscript presented to the American Mathematical Society (December, 1954). Abstract in Bull. Amer. Math. Soc., 61 (1955), 219.

7. E. J. McShane, Linear functionals on certain banach spaces, Proc. Amer. Math. Soc., 1 (1950), 402-408.

8. H. W. Milnes, Convexity of Orlicz spaces, Doctoral dissertation at Wayne University, Detroit, Michigan.

9. W. A. Orlicz, Über eine gewisse Klasse von Räumen vom Typus B, Bull. Acad. Polonaise, (1932), 207-220.

10. A. C. Zaanen, Linear Analysis, Amsterdam, North-Holland Publishing Company, (1953).

WAYNE UNIVERSITY 



\title{
PACIFIC JOURNAL OF MATHEMATICS
}

\author{
EDITORS
}

H. L. Royden

Stanford University

Stanford, California

R. A. Beaumont

University of Washington

Seattle 5, Washington
A. L. Whiteman

University of Southern California

Los Angeles 7, California

E. G. Straus

Unıversity of California

Los Angeles 24, California

\section{ASSOCIATE EDITORS}

\author{
E. F. BECKENBACH \\ C. E. BURGESS \\ M. HALL \\ E. HEWITT
}

\author{
A. HORN \\ V. GANAPATHY IYER \\ R. D. JAMES \\ M. S. KNEBELMAN
}

L. NACHBIN
I. NIVEN
T. G. OSTROM
M. M. SCHIFFER

G. SZEKERES

F. WOLF

K. YOSIDA

\section{SUPPORTING INSTITUTIONS}

UNIVERSITY OF BRITISH COLUMBIA

CALIFORNIA INSTITUTE OF TECHNOLOGY

UNIVERSITY OF CALIFORNIA

MON'TANA STATE UNIVERSITY

UNIVERSITY OF NEVADA

OREGON STATE COLLEGE

UNIVERSITY OF OREGON

UNIVERSITY OF SOUTHERN CALIFORNIA

\author{
STANFORD UNIVERSITY \\ UNIVERSITY OF UTAH \\ WASHINGTON STATE COLLEGE \\ UNIVERSITY OF WASHINGTON \\ AMERICAN MATHEMATICAL SOCIETY \\ CALIFORNIA RESEARCH CORPORATION \\ HUGHES AIRCRAFT COMPANY \\ THE RAMO-WOOLDRIDGE CORPORATION
}

Mathematical papers intended for publication in the Pacific Journal of Mathematics should be typewritten (double spaced), and the author should keep a complete copy. Manuscripts may be sent to any of the editors. All other communications to the editors should be addressed to the managing editor, E. G. Straus at the University of California, Los Angeles 24, California.

50 reprints per author of each article are furnished free of charge; additional copies may be obtained at cost in multiples of 50 .

The Pacific Journal of Mathematics is published quarterly, in March, June, September, and December. The price per volume (4 numbers) is $\$ 12.00$; single issues, $\$ 3.50$. Back numbers are available. Special price to individual faculty members of supporting institutions and to individual members of the American Mathematical Society: $\$ 4.00$ per volume; single issues, $\$ 1.25$.

Subscriptions, orders for back numbers, and changes of address should be sent to Pacific Journal of Mathematics, 2120 Oxford Street, Berkeley 4, California.

Printed at Kokusai Bunken Insatsusha (International Academic Printing Co., Ltd.), No. 10, 1-chome, Fujimi-cho, Chiyoda-ku, Tokyo, Japan.

PUBLISHED BY PACIFIC JOURNAL OF MATHEMATICS, A NON-PROFIT CORPORATION

The Supporting Institutions listed above contribute to the cost of publication of this Journal, but they are not owners or publishers and have no responsibility for its content or policies. 


\section{Pacific Journal of Mathematics}

\section{Vol. 7, No. $3 \quad$ March, 1957}

Silvio Aurora, Multiplicative norms for metric rings............... 1279

Ross A. Beaumont and John Richard Byrne, On the construction of

$R$-modules and rings with polynomial multiplication ............ 1305

Fred Brafman, An ultraspherical generating function . . . . . . . . . . . 1319

Howard Ernest Campbell, On the Casimir operator ............... 1325

Robert E. Edwards, Representation theorems for certain functional

operators..................................... 1333

Tomlinson Fort, The five-point difference equation with periodic

coefficients ..................................... 1341

Isidore Heller, On linear systems with integral valued solutions......... 1351

Harry Hochstadt, Addition theorems for solutions of the wave equation in

parabolic coordinates ................................ 1365

James A. Hummel, The coefficient regions of starlike functions . . . . . . . . 1381

Fulton Koehler, Estimates for the eigenvalues of infinite matrices ......... 1391

Henry Paul Kramer, Perturbation of differential operators ............. 1405

R. Sherman Lehman, Development of the mapping function at an analytic

corner .......................................... 1437

Harold Willis Milnes, Convexity of Orlicz spaces.................. 1451

Vikramaditya Singh, Interior variations and some extremal problems for certain classes of univalent functions . . . . . . . . . . . . . . . . 1485

William Lee Stamey, On generalized euclidean and non-euclidean spaces ............................................. 1505

Alexander Doniphan Wallace, Retractions in semigroups .............. 1513

R. L. Wilder, Monotone mappings of manifolds .................. 1519 